\title{
Modelling the evolution of composition-and stress-depth profiles in austenitic stainless steels during low-temperature nitriding
}

Paper

Jespersen, Freja Nygaard; Hattel, Jesper Henri; Somers, Marcel A. J.

Published in:

Modelling and Simulation in Materials Science and Engineering

Link to article, DOI:

10.1088/0965-0393/24/2/025003

Publication date:

2016

Document Version

Peer reviewed version

Link back to DTU Orbit

Citation (APA):

Jespersen, F. N., Hattel, J. H., \& Somers, M. A. J. (2016). Modelling the evolution of composition-and stressdepth profiles in austenitic stainless steels during low-temperature nitriding: Paper. Modelling and Simulation in Materials Science and Engineering, 24(2), [025003]. https://doi.org/10.1088/0965-0393/24/2/025003

\section{General rights}

Copyright and moral rights for the publications made accessible in the public portal are retained by the authors and/or other copyright owners and it is a condition of accessing publications that users recognise and abide by the legal requirements associated with these rights.

- Users may download and print one copy of any publication from the public portal for the purpose of private study or research.

- You may not further distribute the material or use it for any profit-making activity or commercial gain

- You may freely distribute the URL identifying the publication in the public portal 


\title{
Modelling the evolution of composition- and stress-depth profiles in austenitic stainless steels during low-temperature nitriding
}

\author{
Freja N. Jespersen, J.H. Hattel, M.A.J. Somers* \\ Technical University of Denmark, Department of Mechanical Engineering, Produktionstorvet b. 425, 2800 \\ Kgs. Lyngby, Denmark, *corresponding author: somers@mek.dtu.dk
}

\begin{abstract}
Nitriding of stainless steel causes a surface zone of expanded austenite, which improves the wear resistance of the stainless steel while preserving the stainless behavior. During nitriding huge residual stresses are introduced in the treated zone, arising from the volume expansion that accompanies the dissolution of high nitrogen contents in expanded austenite.

An intriguing phenomenon during low-temperature nitriding is that the residual stresses evoked by dissolution of nitrogen in the solid state, affect the thermodynamics and the diffusion kinetics of nitrogen dissolution. In the present paper solid mechanics was combined with thermodynamics and diffusion kinetics to simulate the evolution of composition-depth and stress-depth profiles resulting from nitriding. The model takes into account a composition-dependent diffusion coefficient of nitrogen in expanded austenite, short range ordering (trapping) of nitrogen atoms by chromium atoms, and the effect of composition-induced stress on surface concentration and diffusive flux. The effect of plasticity and concentrationdependence of the yield stress was also included.
\end{abstract}

Keywords: Nitriding, nitrogen diffusion, expanded austenite, modelling, stress induced diffusion, plasticity

\section{Introduction}

Austenitic stainless steels are widely applied in structural applications because of their corrosion resistance in combination with favourable manufacturing performance. Generally, austenitic stainless steels have poor tribological and wear performance. Low-temperature thermochemical surface engineering by nitriding, carburizing and nitrocarburizing provides a means to drastically improve the tribological/wear performance, without compromising the general corrosion performance and even improving the resistance against localized corrosion, as pitting and crevice corrosion $[1,2,3]$. 
In low-temperature nitriding, carburizing or nitrocarburizing large amounts of nitrogen and/or carbon are dissolved in the surface region. This brings about a zone of expanded austenite, which essentially is a supersaturated solution of nitrogen and/or carbon in austenite. The expanded austenite zone has a substantially higher hardness than the untreated steel and provides drastically improved wear resistance. Furthermore, high compressive residual stresses are introduced, which result in enhanced fatigue performance. A zone of expanded austenite can be achieved by bringing the steel in contact with an environment providing nitrogen and/or carbon, as for example in plasma-assisted or gas-based processing [1,2,3]. The present work is concerned with gas-based nitriding of austenitic stainless steels and modelling the evolution of nitrogendepth and residual stress-depth profiles in relation to the processing parameters. Even though the case investigated is specific for gaseous nitriding, the concepts of the mechanisms governing the evolution of composition and residual stress are claimed to be applicable to (nitro)carburizing and plasma-assisted and liquid processing, as in Kolsterizing ${ }^{\circledR}$, as well.

\section{State-of-the art of modelling low-temperature surface hardening of stainless steel.}

Concentration-depth profiles developing during low temperature nitriding, measured in for example [1], are characterized by the shape shown in Fig. 1: an initially steep decrease in nitrogen content followed by a plateau and a steep decline at the case-core transition. This behaviour deviates from the classical example in textbooks on diffusion showing the composition profile expected for diffusion into a semi-infinite medium with a constant diffusion coefficient (as for example carbon into iron/steel) and constant surface concentration, which obeys the complementary error function. Different approaches have been presented in the literature to explain and model the evolution of such composition-profiles. Parascandola, et al. [4] explained the characteristic nitrogen-concentration profile developing during ion plantation of nitrogen from trapping and detrapping of nitrogen atoms at chromium sites (i.e. short range order of chromium and nitrogen [5]), assuming a constant diffusion coefficient. A satisfactory correspondence was obtained between measured and fitted composition profiles. This mechanism was adopted, extended to include sputtering, and applied to plasma-nitrided single crystals with various orientations by Martinavicius et al. [6]. The assumption of a constant diffusion coefficient in these models contrasts the strong dependence of the nitrogen diffusion coefficient in austenitic stainless steel as determined experimentally on homogeneous thin foils of expanded austenite with various nitrogen contents [7]. Qualitatively, the composition dependence of the diffusion coefficient of nitrogen in expanded austenite can explain the shape of the nitrogen concentration profile developing during nitriding, as demonstrated by calculating the concentration profile from Fick's $2^{\text {nd }}$ law $[8,9,10]$. A better correspondence between calculated and experimental composition-depth profiles was found when trapping of nitrogen atoms was taken into account, as this allows a steeper case-core transition $[8,9,10]$. Moreover, it was demonstrated that the finite rate of the surface reaction, i.e. the decomposition rate of gas species at the surface before incorporation in the solid, as well as the effects of a compressive stress on the solubility of nitrogen in expanded austenite and a compressive stress gradient on the diffusive flux also contribute to the evolution of the concentration-depth profile [10]. 


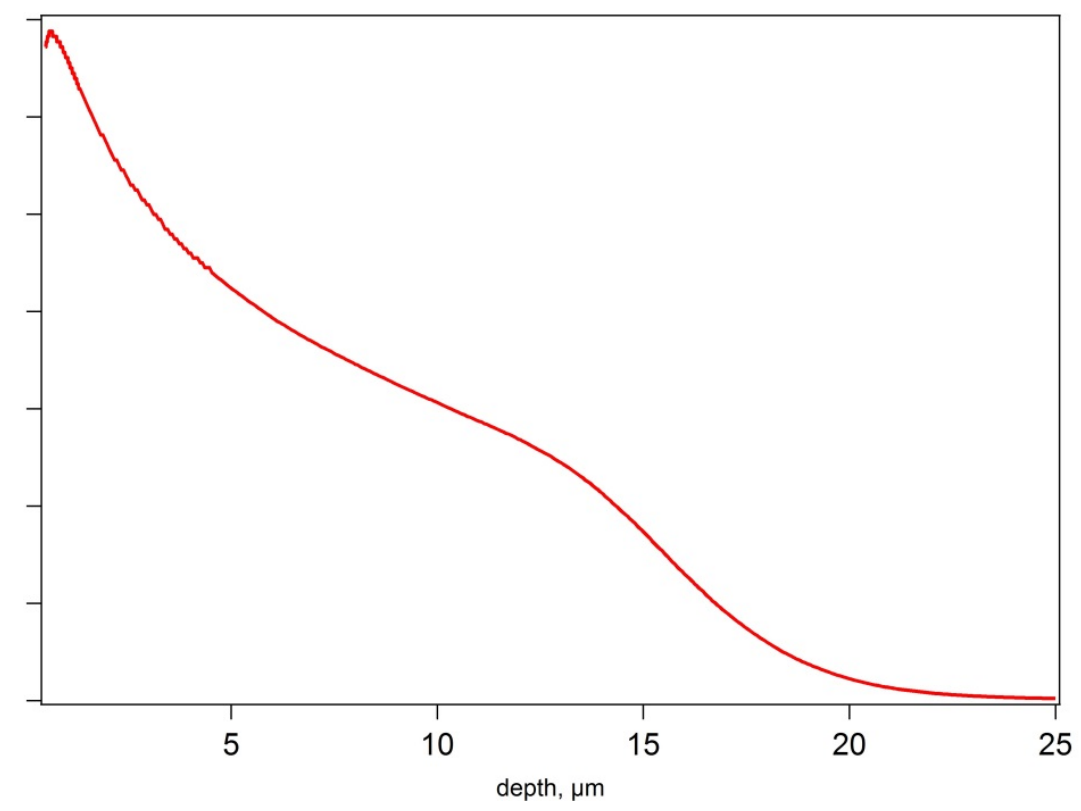

Figure 1 - Typical shape of measured concentration-depth profiles

It is well established that low-temperature nitriding of austenitic stainless steel leads to a composition-induced compressive residual stress depth-profile as a consequence of the lattice expansion associated with the dissolution of interstitial nitrogen and/or carbon. The compressive stresses developing are several GPa's in magnitude, as determined at room temperature after cooling [1,11,12]. Although the stresses at room temperature are mainly composition-induced, a contribution from a difference in linear expansion coefficient between austenite and expanded austenite cannot be excluded, because the expansion coefficient depends on the nitrogen content in expanded austenite [13].

Christiansen and Somers showed that the enormous residual stress gradient can augment the depth range of the expanded austenite zone by a factor of 2 [14]. The effect of residual stress on the nitrogen concentration profile was also recognized by Galdikas and Moskalioviene. They modelled the influence of a residual stress gradient on the concentration profile for the case of a constant as well as for a composition-dependent diffusion coefficient, assuming that the lattice misfit associated with nitrogen dissolution is elastically accommodated $[15,16]$. In their model a linear relation between residual stress and nitrogen concentration profile was assumed. For this purpose they adopted an unphysical proportionality parameter originally proposed by Christiansen and Somers [17] for the purpose of estimating artefacts on X-ray stress determination. In the pragmatic approach by Galdikas and Moskalioviene [15,16], no actual physical coupling occurs between the concentration-depth profile and mechanical equilibrium considerations. Furthermore, in [15,16] a diffusion coefficient continuously decreasing with nitrogen concentration was assumed (which approaches infinity for very low nitrogen contents!), rather than the dependence showing an increase with nitrogen content and a decrease as determined experimentally from diffusion in stress-free foils of uniform composition [7]. 
Experimentally, it has been demonstrated from lattice rotations and associated texture changes in expanded austenite as well as from enhanced surface roughness by grain push-out, that, at least part of the composition-induced stress is accommodated plastically during nitriding [18,19,20,21]. Biaxial compressive stress levels of several GPa's, as observed experimentally, clearly exceed by far the yield stress of austenitic stainless steel. The high compressive stresses measured are explained from solid-solution strengthening of austenite by the presence of nitrogen, which implies that the yield stress is augmented importantly by the dissolution of nitrogen. The occurrence of plastic accommodation of composition-induced stress is therefore the result of a competition between strengthening and stress build-up. Apparently, for nitriding (and nitrocarburizing) the stress build up exceeds the yield stress achievable by solid-solution strengthening. Note that the occurrence of plastic accommodation of composition-induced stresses has so far not been observed for carburizing of stainless steel. This indicates that in carbon-expanded austenite the strengthening effect dominates over the composition induced stress build-up for the (narrower) composition range under consideration.

A better understanding of the stress-assisted diffusion controlled growth of the expanded austenite case and the associated evolution of the substantial composition-induced stresses is crucial for an accurate prediction of the concentration-depth and stress-depth profiles.

In the present work the interdependent influences of composition and stress on the evolution of nitrogen concentrationdepth profiles and stress-depth profiles in expanded austenite zones are modelled. The model includes:

- a concentration-dependent diffusion coefficient of nitrogen in expanded austenite;

- trapping of nitrogen atoms by chromium atoms;

- the kinetics of the surface reaction;

- the effect of composition-induced stress on the nitrogen solubility in expanded austenite;

- the effect of a composition-induced stress gradient on the diffusive flux;

- the effect of the competition between solid-solution strengthening and compressive stress build-up to account for the occurrence of plastic deformation.

In contrast with previous work by for example Christiansen et al. [10] or Galdikas and Moskalioviene [15] the model presented here calculates stress based on mechanical equilibrium principles and considers elasto-plasticity.

Apart from the kinetics of the surface reactions the concepts investigated here can be directly transferred to plasma nitriding as well, albeit that plasma nitriding requires a consideration of the sputtering effects at the surface. It is beyond the scope of the present work to discuss such peculiarities of plasma-surface interactions. 


\section{Basic equations of the model}

The present work assumes 1-dimensional diffusion of nitrogen in the depth-direction, with reference to a flat surface. Consequently, the influence of corners and curved surfaces is not considered.

\subsection{Basic diffusion equations}

The diffusive flux of nitrogen atoms in the direction $\mathrm{z}$ under the influence of a chemical potential gradient of this species, $\frac{\partial \mu_{N}}{\partial z}$, is defined as [22]

$$
\mathrm{J}=-\mathrm{M}_{N} \mathrm{c}_{N} \frac{\partial \mu_{N}}{\partial \mathrm{z}}
$$

where $\mathrm{c}_{\mathrm{N}}$ is the nitrogen concentration in mol.m ${ }^{-3}, \mu_{N}$ is the chemical potential of nitrogen in $\mathrm{J}_{\mathrm{mol}}{ }^{-1}$ and $\mathrm{M}_{\mathrm{N}}$ is the mobility of nitrogen in $\mathrm{m}^{2} . \mathrm{s}^{-1}$ given by [22]

$$
M_{N}=\frac{D_{N}}{R T}
$$

where $D_{N}$ is the intrinsic diffusion coefficient of nitrogen in $\mathrm{m}^{2} \cdot \mathrm{s}^{-1}, \mathrm{R}$ is the gas constant in $\mathrm{J} \cdot \mathrm{mol}^{-1} \cdot \mathrm{K}^{-1}$ and $\mathrm{T}$ is the temperature in $\mathrm{K}$.

Generally, the chemical potential is assumed to depend on the concentration only

$$
\mu\left(c_{N}\right)=\mu_{0}+R T \ln \left(c_{N}\right)
$$

In which case Eq. 1 reduces to Fick's first law

$$
\mathrm{J}_{N}=-\mathrm{D}_{N} \frac{\partial \mathrm{c}_{N}}{\partial \mathrm{z}}
$$

More generally, the chemical potential is a function of the activity of nitrogen, $\mathrm{a}_{\mathrm{N}}$, and the hydrostatic stress (pressure), $\sigma_{H}$, and the temperature $\mathrm{T}[23,24]$

$$
\mu_{N}\left(a_{N}, \sigma_{H}, T\right)=\mu_{N, 0}+R T \ln \left(a_{N}\right)-V_{N} \sigma_{H}
$$

where $\mu_{N, 0}$ is the chemical potential of nitrogen in the reference state with respect to which $\mathrm{a}_{\mathrm{N}}$ is defined ${ }^{1}, V_{N}$ is the partial molar volume of nitrogen. It is noted that in principle $\mathrm{a}_{\mathrm{N}}, \mathrm{V}_{\mathrm{N}}$ and $\sigma_{H}$ depend on the temperature. Assuming that diffusion occurs at constant temperature and that no temperature gradients are present, the diffusive flux follows from inserting Eq. 5 and Eq.2 into Eq. 1, which results in

\footnotetext{
${ }^{1}$ Usually, for nitrogen in solid solution the reference state is taken as nitrogen gas at 1 bar at the temperature under consideration.
} 


$$
J_{N}=-\frac{D_{N} c_{N}}{R T}\left(\frac{\partial \mu_{N}}{\partial c_{N}} \frac{\partial c_{N}}{\partial z}+\frac{\partial \mu_{N}}{\partial \sigma_{H}} \frac{\partial \sigma_{H}}{\partial z}\right)
$$

In a Fe-N phase the activity is linearly proportional to the nitriding potential, $K_{N}=\frac{p_{N H_{3}}}{p_{H_{2}}{ }^{3 / 2}}$, by [25]

$$
a=K_{T}^{\varphi} K_{N}
$$

where $K_{T}^{\varphi}(T, p)$ is the temperature and pressure dependent equilibrium constant for the reaction describing the dissolution of $\mathrm{N}$ into the solid phase $\varphi$ from a gas containing $\mathrm{NH}_{3}$ and $\mathrm{H}_{2}$.

Since the activity depends on the concentration

$$
\frac{\partial \mu_{N}}{\partial c_{N}}=R T \frac{\partial \ln a_{N}}{\partial c_{N}}=\frac{R T}{c_{N}} \frac{\partial \ln \left(a_{N}\right)}{\partial \ln \left(c_{N}\right)}=\frac{R T}{c_{N}} \frac{\partial \ln \left(K_{T}^{\varphi} K_{N}\right)}{\partial \ln \left(c_{N}\right)}
$$

Realizing that $K_{T}^{\varphi}$ only depends on pressure and temperature and not on nitrogen concentration, it is obtained

$$
\frac{\partial \mu_{N}}{\partial c_{N}}=\frac{R T}{K_{N}} \frac{\partial K_{N}}{\partial c_{N}}
$$

Inserting Eq. 9 into Eq. 6 and inserting $\frac{\partial \mu_{N}}{\partial \sigma_{H}}=-V_{N}$ (cf. Eq.5), the following generalized form of Fick's 1st law is obtained

$$
J_{N}=-\frac{D_{N} c_{N}}{R T}\left(\frac{R T}{K_{N}} \frac{\partial K_{N}}{\partial c_{N}} \frac{\partial c_{N}}{\partial z}-V_{N} \frac{\partial \sigma_{H}}{\partial z}\right)
$$

Accordingly, the generalized form of Fick's $2^{\text {nd }}$ law is

$$
\frac{\partial c_{N}}{\partial t}=-\frac{\partial}{\partial z}\left(-D_{N}^{(c)} \cdot \frac{\partial c_{N}}{\partial z}+\frac{D_{N} \cdot c_{N}}{R T} \cdot V_{N} \cdot \frac{\partial \sigma_{H}}{\partial z}\right)
$$

where $D_{N}^{(c)}$ represents the concentration dependence of the diffusion coefficient of nitrogen, i.e. $D_{N}$ times the thermodynamic factor $\left(\frac{c_{N}}{K_{N}} \frac{\partial K_{N}}{\partial c_{N}}\right)$. When $D_{N}^{(c)}$ is a known explicit function of the concentration the equation can be rewritten to

$$
\frac{\partial c_{N}}{\partial t}=-\frac{\partial}{\partial z}\left(-D_{N}^{(c)} \cdot \frac{\partial c_{N}}{\partial z}+\frac{D_{N}^{(c)}}{\frac{\partial K_{N}}{\partial c_{N}}} \cdot \frac{K_{N}}{R T} \cdot V_{N} \cdot \frac{\partial \sigma_{H}}{\partial z}\right)
$$

and then the differentiation with respect to $\mathrm{z}$ gives

$$
\frac{\partial c_{N}}{\partial t}=\frac{\partial D_{N}^{(c)}}{\partial c_{N}} \cdot\left(\frac{\partial c_{N}}{\partial z}\right)^{2}+D_{N}^{(c)} \cdot \frac{\partial^{2} c_{N}}{\partial z^{2}}-\frac{\partial}{\partial z}\left(D_{N}^{(c)} \cdot \frac{K_{N}}{\frac{\partial K_{N}}{\partial c_{N}}}\right) \cdot \frac{V_{N}}{R T} \frac{\partial \sigma_{H}}{\partial z}-D_{N}^{(c)} \cdot\left(\frac{K_{N}}{\partial K_{N}} \frac{V_{N}}{R T} \frac{\partial^{2} \sigma_{H}}{\partial z^{2}}\right)
$$




\subsection{Trapping}

The short-range ordering of nitrogen atoms by chromium is referred to as trapping and is mathematically treated analogously to nitrogen precipitation as in [10,26,27]. It is assumed that trapping first occurs above a certain threshold probability for finding a $\mathrm{Cr}-\mathrm{N}$ pair of atoms. Analogous to the solubility product of nitrogen and chromium contents above which $\mathrm{CrN}$ precipitation occurs, the thermodynamic solubility constant, $\mathrm{K}_{\mathrm{e}}$, is introduced to describe the solubility product of nitrogen and chromium contents above which trapping of nitrogen atoms occurs. Suppression of the actual precipitation of chromium nitride through sluggish diffusion kinetics of chromium diffusion is the very essence of supersaturated, metastable expanded austenite during low temperature nitriding (and/or carburizing) of stainless steel. Prolonged nitriding or subsequent ageing will eventually lead to the unintentional but unavoidable precipitation of CrN.

The equilibrium constant of trapping nitrogen by chromium is described by:

$$
K_{e}=\frac{1}{c_{C r} \cdot c_{N}^{n}}=\frac{1}{K_{C r N}} \rightarrow K_{C r N}=c_{C r} \cdot c_{N}^{r}
$$

where $C_{j}$ is the concentration of the dissolved element $j$ and $K_{C r N}$ is the solubility product of $C r$ and $N$ with $r$ being the number of nitrogen atoms per chromium atom, which is about $\mathrm{Cr}: \mathrm{N}=1: 0.9$ for strong binding of nitrogen to chromium in AISI 316L [21]. In the present work $r=1$ was assumed.

\subsection{Diffusion boundary condition at the gas/solid interface}

The concentration of nitrogen at the surface of expanded austenite during gaseous nitriding depends on the balance of the fluxes of nitrogen atoms at the surface [28]. The flux of nitrogen atoms arriving at the surface can usually be assumed to be governed by the dissociation kinetics of nitrogen-containing species at the surface (as ammonia). The fluxes of nitrogen atoms leaving from the surface are the diffusive flux of nitrogen into the solid state and the flux of $\mathrm{N}_{2}$ molecules desorbing from the surface after association of adsorbed $\mathrm{N}$ atoms. The latter can be omitted for low temperature nitriding of stainless steel $(\mathrm{T}<723 \mathrm{~K})$, but has been observed to play an important role at higher temperatures and high ammonia contents [29]. The flux of nitrogen atoms arriving at the surface $J_{N}^{s}$ is given by $[28,30]$

$$
J_{\text {surf }}=k \cdot\left(c_{N}^{e q}-c_{N}^{s}\right)
$$

where $c_{N}^{s}$ is the concentration of nitrogen just below the surface, $c_{N}^{e q}$ is the nitrogen concentration in the solid phase at the surface that would prevail if imposed equilibrium would be attained between nitrogen in the gas phase and nitrogen in solid solution, i.e. the chemical potentials of nitrogen in the gas-phase and in solid solution are equal; $k$ is the reaction-rate constant of the slowest step in the ammonia dissociation [30]. 
At the surface the concentration can then be found from the continuity equation for balancing the arriving and leaving nitrogen fluxes:

$$
\frac{\partial c_{N}^{s}}{\partial t}=-\frac{\partial J_{N}^{s}}{\partial z}=-\left(\frac{\partial J_{N}^{s, d i f f}}{\partial z}-\frac{\partial J_{N}^{s, d i s s}}{\partial z}\right)
$$

where $J_{N}^{s, \text { diss }}$ and $J_{N}^{s, \text { diff }}$ are the fluxes of nitrogen atoms arriving at the surface (from dissociation) and leaving from the surface by diffusion, respectively.

\subsection{Calculation of stress}

The strain arising from the expansion of the austenite lattice as caused by the dissolution of interstitial nitrogen, i.e. the chemical-induced strain, $\varepsilon_{i j}^{c h}$, is defined as

$$
\begin{array}{r}
\text { for } i=j: \quad \varepsilon_{i j}^{c h}(c)=\frac{V(c)^{1 / 3-V_{r e f}^{1 / 3}}}{V_{r e f}^{1 / 3}} \\
\text { for } i \neq j: \quad \varepsilon_{i j}^{c h}=0
\end{array}
$$

where $\mathrm{V}(\mathrm{c})$ in the concentration-dependent volume of (expanded) austenite per metal atom in $\mathrm{m}^{3}$ and $\mathrm{V}_{\text {ref }}$ indicates the volume per metal atom of the interstitial-free lattice of austenite.

The total strain, $\varepsilon_{i j}^{\text {tot }}$, is then given by [31]

$$
\varepsilon_{i j}^{t o t}=\varepsilon_{i j}^{m e c h}+\varepsilon_{i j}^{c h}+\varepsilon_{i j}^{t h}
$$

where $\varepsilon_{i j}^{t h}$ is the thermal strain and $\varepsilon_{i j}^{m e c h}$ is the mechanical strain which is the sum of the elastic and plastic strain.

A simple description of the stress state in the surface can be found by applying a method equivalent to that described by Hattel and Hansen [31,32], with the following assumptions (note that the sample is an infinitely large plate with parallel flat surfaces):

- the surface of the sample is homogeneous and can move freely: $\sigma_{33}=\sigma_{\perp}=0$ ( $\sigma_{\perp}$ is the stress normal to the surface);

- $\quad$ the stress state in the surface is rotationally symmetric, hence the normal stresses in the surface plane are equal $\sigma_{11}=\sigma_{22}=\sigma_{\|}\left(\sigma_{\|}\right.$is the stress parallel to the surface); 
- $\quad$ the specimen does not bend, hence uniform expansion at all depths: $\varepsilon_{11}^{\text {tot }}=\varepsilon_{22}^{\text {tot }}=\varepsilon_{\|}^{\text {tot }}$ and $\varepsilon_{12}^{\text {tot }}=\varepsilon_{13}^{\text {tot }}=\varepsilon_{23}^{\text {tot }}=$ 0 , and thus $\sigma_{12}=\sigma_{13}=\sigma_{23}=0$

- $\quad$ there are no temperature gradients in the sample, hence no thermal strains.

Using these assumptions and assuming, for the time being, purely elastic stresses, the following relation can be found between the in-plane stresses and strain in the surface region

$$
\sigma_{\|}^{e l}=\frac{E}{1-v}\left(\varepsilon_{\|}^{t o t}-\varepsilon_{\|}^{c h}\right)
$$

where $E$ is Young's modulus and $v$ is Poisson's ratio. The total strain $\varepsilon_{\|}^{\text {tot }}$ can be found from considering mechanical equilibrium over the cross-section of the sample, which for the case that the stress state is mirror-symmetrical with respect to the plane at half the sample thickness (total sample thickness is $2 \mathrm{~L}$ ). Note that nitrogen is assumed to diffuse from two parallel surfaces on either side of the sample towards the centre of the sample, and thus mirror-symmetry is assumed and considering one side suffices for the calculations. Hence,

$$
\int_{0}^{L} \sigma_{\|} d z=0
$$

Inserting Eq. 18 into Eq. 19, and assuming that Young's modulus, E, and the Poisson ratio, $v$, are independent of depth ${ }^{2}$, yields

$$
\frac{E}{1-v} \int_{0}^{L}\left(\varepsilon_{\|}^{t o t}-\varepsilon_{\|}^{c h}\right) d z=0
$$

Since it was assumed that $\varepsilon_{22}^{t o t}=\varepsilon_{11}^{t o t}$ is constant in space and varies in time, this gives

$$
\varepsilon_{\|}^{t o t}=\frac{1}{L} \int_{0}^{L}\left(\varepsilon_{\|}^{c h}\right) d z
$$

It is noted that a similar method was applied in [10,33,34], albeit that the total strain was taken equal to zero. This is a reasonable assumption, provided that the depth range where chemical strains apply is infinitely thin as compared to the depth range of the sample (cf. section 4.3). This assumption drastically simplifies the mathematical equations, resulting in the following equation for calculating the stress

$$
\sigma_{\|}=-\frac{E}{1-v} \varepsilon_{\|}^{c h}
$$

\footnotetext{
${ }^{2}$ No quantitative data is available for the composition dependence of Young' modulus and the Poisson constant for expanded austenite. Therefore we approximate it with the known values for austenite in this work.
} 


\subsection{Plastic accommodation of stress}

If the strains are no longer accommodated purely elastically, but lead to plastic deformation as well, the stresses can no longer be calculated directly, since the stress depends on the loading path. Thus an incremental formulation is used. The relation between the incremental stress $\dot{\sigma}_{i j}$ and the incremental mechanical strain $\dot{\varepsilon}_{k l}$ is

$$
\dot{\sigma}_{i j}=L_{i j k l} \dot{\varepsilon}_{k l}
$$

where $L_{i j k l}$ is the incremental stiffness tensor which, according to $\mathrm{J}_{2}$-flow theory [35], is given by

$$
L_{i j k l}=\frac{E}{1+v}\left[\frac{1}{2}\left(\delta_{i k} \delta_{j l}+\delta_{i l} \delta_{j k}\right)+\frac{v}{1-2 v} \delta_{i j} \delta_{k l}-\beta \frac{3}{2} \frac{E / E_{t}-1}{E / E_{t}-(1-2 v) / 3} \frac{s_{i j} s_{k l}}{\sigma_{e}^{2}}\right]
$$

where $\mathrm{E}$ is Young's modulus, $\mathrm{E}_{\mathrm{t}}$ is the tangent modulus, $v$ is Poisson's ratio and $\delta_{\mathrm{ij}}$ is Kronecker's delta and $\beta=0$ for elastic problems and $\beta=1$ if there is plastic flow.

The stress deviator tensor, $\mathrm{s}_{\mathrm{ij}}$, is given by [35]

$$
s_{i j}=\sigma_{i j}-\delta_{i j} \frac{\sigma_{k k}}{3}
$$

and the von Mises yield surface is described by [35]

$$
\sigma_{e}^{2}=\frac{3}{2} s_{i j} s_{i j}
$$

The maximal von Mises stress depends on the loading path and is changed if the actual von Mises stress exceeds the preceding maximum von Mises stress (strengthening):

$$
\text { if } \sigma_{e} \geq \sigma_{e, \max } \text { then } \sigma_{e, \max }=\sigma_{e}
$$

The von Mises stress increment $\dot{\sigma}_{e}$ is found from the incremental stresses $\left(\dot{\sigma}_{k l}\right)$ [35]:

$$
\dot{\sigma}_{e}=\frac{3 \cdot s_{k l} \cdot \dot{\sigma}_{k l}}{2 \cdot \sigma_{e}}
$$

The values for $\beta$ can now be determined from the flow criteria, in $\mathrm{J}_{2}$ flow theory [35]:

$$
\begin{aligned}
\text { for } \sigma_{e}=\sigma_{e, \max } \text { and } \dot{\sigma}_{e} \geq 0 & \beta=1 \\
\text { if } \sigma_{e}<\sigma_{e, \max } \text { or } \dot{\sigma}_{e}<0 & \beta=0
\end{aligned}
$$


Since $\beta$ depends on the stresses, in this work the $\beta$ calculated in the preceding step is used to determine the state and hence stresses in the next step. This means that no equilibrium iterations are performed and thus a small overshoot will occur at the time of changing from elasticity to plasticity. For the monotone loading seen for nitriding, the overshoot can be minimized (neglected) using sufficiently small increments.

The tangent modulus is found using a power hardening law [35], which states that

$$
\text { for } \sigma>\sigma_{y}, \varepsilon=\frac{\sigma_{y}}{E}\left(\frac{\sigma}{\sigma_{y}}\right)^{n}
$$

Since $\frac{1}{E_{t}}=\frac{d \varepsilon}{d \sigma}$ this means that, using von Mises criterion of plasticity, the tangent modulus, $E_{t}$, is given by:

$$
E_{t}=\frac{E}{n}\left(\frac{\sigma_{y}}{\sigma_{e}}\right)^{n-1}
$$

The new stress is found by adding the incremental stress to the stress from the preceding step

$$
\sigma_{i j}^{t+\Delta t}=\sigma_{i j}^{t}+\dot{\sigma_{l j}}
$$

Analogous to the purely elastic case, assuming equi-biaxial plane stress state, gives the following expression for the von Mises stress

$$
\sigma_{e}^{2}=\frac{3}{2}\left(s_{11}^{2}+s_{22}^{2}+s_{33}^{2}\right)=\sigma_{22}^{2}
$$

Since the out of plane stress is zero, $\sigma_{33}=0$, it follows immediately $\dot{\sigma}_{33}=0$, and the von Mises stress increment is then

$$
\dot{\sigma}_{e}=\frac{3\left(s_{11} \dot{\sigma}_{11}+s_{22} \dot{\sigma}_{22}+s_{33} \dot{\sigma}_{33}\right)}{2 \cdot \sigma_{e}}=\frac{3\left(\frac{\sigma_{22}}{3} \dot{\sigma}_{22}+\frac{\sigma_{22}}{3} \dot{\sigma}_{22}-\frac{2 \sigma_{22}}{3} \cdot 0\right)}{2 \cdot\left|\sigma_{22}\right|}
$$

and thus

$$
\begin{array}{r}
\text { for } \sigma_{22}>0, \quad \dot{\sigma}_{e}=\dot{\sigma}_{22} \\
\text { for } \sigma_{22}<0, \quad \dot{\sigma}_{e}=-\dot{\sigma}_{22}
\end{array}
$$

Since $\varepsilon_{11}=\varepsilon_{22}$ it holds that $\dot{\varepsilon}_{11}=\dot{\varepsilon}_{22}$ and then the expressions for the incremental stress components become

$$
\begin{aligned}
\dot{\sigma}_{\|}=\dot{\sigma}_{11}=\dot{\sigma}_{22}= & \frac{E}{1+v}\left[\frac{v}{1-2 v}-\beta \frac{1}{6} \frac{E / E_{t}-1}{E / E_{t}-(1-2 v) / 3}\right] \dot{\varepsilon}_{22}+\frac{E}{1+v}\left[1+\frac{v}{1-2 v}-\beta \frac{1}{6} \frac{E / E_{t}-1}{E / E_{t}-(1-2 v) / 3}\right] \dot{\varepsilon}_{22} \\
& +\frac{E}{1+v}\left[\frac{v}{1-2 v}+\beta \frac{1}{3} \frac{E / E_{t}-1}{E / E_{t}-(1-2 v) / 3}\right] \dot{\varepsilon}_{33}
\end{aligned}
$$




$$
\begin{aligned}
\dot{\sigma}_{\perp}=\dot{\sigma}_{33}=\frac{E}{1+v} & {\left[\frac{v}{1-2 v}-\beta \frac{3}{2} \frac{E / E_{t}-1}{E / E_{t}-(1-2 v) / 3} \frac{-2}{9}\right] \dot{\varepsilon}_{22}+\frac{E}{1+v}\left[\frac{v}{1-2 v}-\beta \frac{3}{2} \frac{E / E_{t}-1}{E / E_{t}-(1-2 v) / 3} \frac{-2}{9}\right] \dot{\varepsilon}_{22} } \\
+ & \frac{E}{1+v}\left[1+\frac{v}{1-2 v}-\beta \frac{3}{2} \frac{E / E_{t}-1}{E / E_{t}-(1-2 v) / 3} \frac{4}{9}\right] \dot{\varepsilon}_{33}
\end{aligned}
$$

Because of the free surface $\sigma_{33}=0$ at all times, thus $\dot{\sigma}_{33}=0$ and restructuring Eq. 36 gives an expression for $\dot{\varepsilon}_{33}$ as a function of $\dot{\varepsilon}_{22}$

$$
\dot{\varepsilon}_{33}=-\frac{\left[2 \frac{v}{1-2 v}+\beta \frac{2}{3 E / E_{t}-(1-2 v) / 3}\right]}{\left[1+\frac{v}{1-2 v}-\beta \frac{2}{3 E / E_{t}-(1-2 v) / 3}\right]} \dot{\varepsilon}_{22}
$$

Inserting this interdependence of $\dot{\varepsilon}_{33}$ and $\dot{\varepsilon}_{22}$ in the expression for the in-plane incremental stress tensors, it follows for the case of plasticity, $\beta=1$, that

$$
\dot{\sigma}_{11}=\dot{\sigma}_{22}=\frac{E}{1+v}\left(\left[1+2 \frac{v}{1-2 v}-\frac{1}{3} \frac{E / E_{t}-1}{E / E_{t}-(1-2 v) / 3}\right]+\frac{-2\left[\frac{v}{1-2 v}+\frac{1}{3 E / E_{t}-(1-2 v) / 3}\right]^{2}}{\left[1+\frac{v}{1-2 v}-\frac{2}{3 E / E_{t}-(1-2 v) / 3}\right]}\right) \dot{\varepsilon}_{22}
$$

and for elasticity, $\beta=0$,

$$
\dot{\sigma}_{11}=\dot{\sigma}_{22}=\frac{E}{1-v} \dot{\varepsilon}_{22}
$$

where the mechanical incremental strain, $\dot{\varepsilon}_{22}$, is found by

$$
\dot{\varepsilon}_{22}^{t o t}=\dot{\varepsilon}_{22}+\dot{\varepsilon}_{22}^{c h}
$$

The total strain increment $\dot{\varepsilon}_{22}^{\text {tot }}$ can be found using equilibrium of the stress increment $\dot{\sigma}_{22}$ over the cross-section from the surface to the depth $L$

$$
\int_{0}^{L} \dot{\sigma}_{22} d z=0
$$

Since there are now both a plastic region from the surface to a depth $z_{p l}$ and an elastic region from $z_{p l}$ to the maximum depth, $\mathrm{L}$, the integral is split as follows

$$
\int_{0}^{L} \dot{\sigma}_{22} d z=\int_{0}^{z} z_{p l} \dot{\sigma}_{22} d z+\int_{z p l}^{L} \dot{\sigma}_{22} d z
$$

This results in the following form of the equilibrium equation 


$$
\int_{0}^{z}{ }^{p l} \dot{\sigma}_{22} d z+\int_{z p l}^{L} \dot{\sigma}_{22} d z=0
$$

Assuming constant material parameters $(E, v)$ and inserting the expressions for the stress in elastic (Eq. 39) and the plastic regions (Eq.38) in Eq. 43 gives

$$
\begin{aligned}
& \dot{\varepsilon}_{22}^{t o t}=\left[\frac{E}{1+v}\left(\left[1+2 \frac{v}{1-2 v}-\frac{1}{3} \frac{\frac{E}{E_{t}}-1}{\frac{E}{E_{t}}-\frac{(1-2 v)}{3}}\right]+\frac{-2\left[\frac{v}{1-2 v}+\frac{1}{3} \frac{\frac{E}{E_{t}}-1}{\frac{E}{E_{t}}-\frac{(1-2 v)}{3}}\right]}{\left[1+\frac{v}{1-2 v}-\frac{2}{3} \frac{\frac{E}{E_{t}}-1}{\frac{E}{E_{t}}-\frac{(1-2 v)}{3}}\right]}\right] \int_{0}^{z_{p l}} \dot{\varepsilon}_{22}^{c h} d z+\frac{E}{1-v} \int_{z_{p l}}^{L} \dot{\varepsilon}_{22}^{c h} d z\right] \\
& /\left[\frac { E } { 1 + v } \left(\left[1+2 \frac{v}{1-2 v}-\frac{1}{3} \frac{\frac{E}{E_{t}}-1}{\frac{E}{E_{t}}-\frac{(1-2 v)}{3}}\right]+\frac{-2\left[\frac{v}{1-2 v}+\frac{1}{3} \frac{\frac{E}{E_{t}}-1}{\frac{E}{E_{t}}-\frac{(1-2 v)}{3}}\right]^{2}}{\left[1+\frac{v}{1-2 v}-\frac{2}{3} \frac{\frac{E}{E_{t}}-1}{\frac{E}{E_{t}}-\frac{(1-2 v)}{3}}\right]} z_{p l}\right.\right. \\
& +\frac{E}{1-v}\left(L-z_{p l}\right)
\end{aligned}
$$




\section{Computational Method}

\subsection{Computation of composition profiles}

Composition profiles were computed with the finite difference method. Discretizing was done using the central explicit finite-difference method giving for Eq. 12:

$$
\begin{aligned}
& \frac{c_{i}^{t+\Delta t}-c_{i}^{t}}{\Delta t}=\frac{\partial D_{N}^{\left(c_{i}^{t}\right)}}{\partial c}\left(\frac{c_{i+1}^{t}-c_{i-1}^{t}}{2 \Delta z}\right)^{2}+D_{N}^{\left(c_{i}^{t}\right)} \cdot \frac{c_{i+1}^{t}-2 c_{i}^{t}+c_{i-1}^{t}}{\Delta z^{2}}-\frac{\left(D_{N}^{\left(c_{i+1}^{t}\right)} \cdot \frac{K_{N_{i+1}}}{\frac{\partial K_{N_{i+1}}}{\partial c_{N}}}-D_{N}^{\left(c_{i-1}^{t}\right)} \cdot \frac{K_{N_{i-1}}}{\frac{\partial K_{N_{i-1}}}{\partial c_{N}}}\right)}{2 \Delta z} \frac{\sigma_{H i+1}^{t}-\sigma_{H i-1}^{t}}{2 \Delta z} \\
& -D_{N}^{\left(c_{i}^{t}\right)}\left(\frac{K_{N_{i}}}{\frac{\partial K_{N_{i}}}{\partial c_{N}}} \frac{V_{N}}{R T} \frac{\sigma_{H i+1}^{t}-2 \sigma_{H i}^{t}+\sigma_{H i-1}^{t}}{\Delta z^{2}}\right)
\end{aligned}
$$

where $D_{N}^{\left(c_{i}^{t}\right)}$ is a known explicit function of the concentration, giving the possibility of calculating $\frac{\partial D}{\partial c}$ for a known concentration $c_{i}^{t}$.

The continuity equation at the surface to balance the fluxes of nitrogen atoms arriving at and leaving from the surface cell to calculate the actual surface concentration of nitrogen, described by Eq. 15, can be discretized as

$$
\frac{c_{i}^{t+\Delta t}-c_{i}^{t}}{\Delta t}=-\frac{J_{i \rightarrow i+1}-J_{\text {surf }}}{\Delta z}
$$

Combining Eq. 46 with the expression for $J_{\text {surf }}$, given in Eq. 14 and the expression for the flux, (see Eq. 10 and $11 \mathrm{~b}$ ) the nitrogen concentration in the surface cell follows from

$$
\frac{c_{i}^{t+\Delta t}-c_{i}^{t}}{\Delta t}=D_{N}^{\left(c_{i}^{t}\right)} \frac{c_{i+1}^{t}-c_{i}^{t}}{\Delta z_{i}^{2}}-D_{N}^{\left(c_{i}^{t}\right)} \frac{K_{N_{i}}}{\frac{\partial K_{N_{i}}}{\partial c_{N}}} \frac{V_{N}}{R T} \frac{\sigma_{H}^{t}{ }_{i+1}^{t}-\sigma_{H}^{t}}{\Delta z_{i}^{2}}+\frac{k}{\Delta z_{i}} \cdot\left(c_{e q}-c_{i}^{t}\right)
$$

A Flow chart of the computational sequence is shown in Fig. 2. 
Inputs

Grid inputs: element sizes

Material parameters: Young's modulus, Poisson's ratio, $V_{0}$ of unit-cell, $V_{N}$, power hardening law parameter ( $n$ ), surface diffusion coefficient Initial values: stress, strain, concentration, Yield stress

Constants: Temperature, gas-constant, nitriding potential

Trapping parameters: chromium concentration, $n$, trapping parameter $\mathrm{K}_{\mathrm{MeN}}$

Number and size of time steps

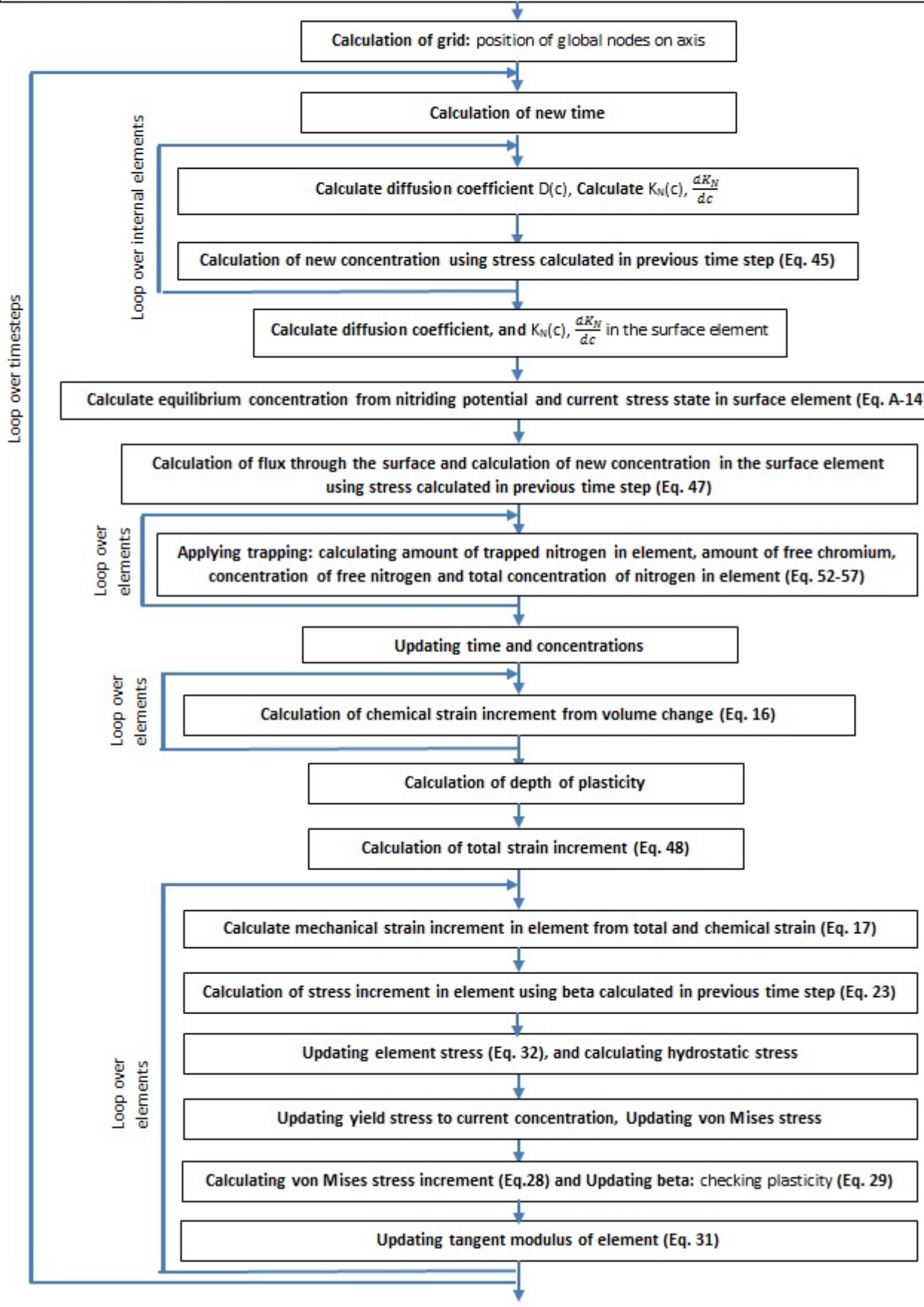

Figure 2 - Computational flowchart 


\subsection{Computation of strains and stresses}

The computation of composition-induced strains and stresses is done straightforwardly for each element after the concentration is calculated in each time-step. However since $\beta$ depends on the stresses, this work uses the beta calculated in the preceding step to determine the state and hence stresses. This means that a small overshoot will occur at the time of changing from elasticity to plasticity, but with the monotone loading and using sufficiently small increments the overshoot can be neglected.

The computation of the integrals used for finding the total strains as in for example Eq. 21 is done using the following numerical integration

$$
\varepsilon_{\|}^{t o t}=\frac{1}{L} \int_{0}^{L}\left(\varepsilon_{\|}^{c h}\right) d z=\frac{1}{L} \sum_{1}^{\text {imax }}\left[\varepsilon_{22}^{c h}(i) \cdot \Delta z(i)\right]
$$

where $i$, is the element number and imax, is the number of the element ending at the depth $L$.

Similarly the integrals used for calculating the total strain when there is plasticity (Eq. 44)

is calculated using a similar numerical integration

$$
\begin{aligned}
& \int_{0}^{z_{p l}} \dot{\varepsilon}_{22}^{c h} d z=\sum_{1}^{i_{\text {max }, p l a s t i c}}\left[\dot{\varepsilon}_{22}^{c h}(i) \cdot \Delta z(i)\right] \\
& \int_{z_{p l}}^{L} \dot{\varepsilon}_{22}^{c h} d z=\sum_{i_{\text {max }} \text { plastic }}^{\text {imax }}\left[\dot{\varepsilon}_{22}^{c h}(i) \cdot \Delta z(i)\right]
\end{aligned}
$$

For the case of expanded austenite, where no nucleation or precipitation of a new phase occurs, the chemical strain can be calculated directly from the total nitrogen concentration by

$$
\begin{gathered}
\text { for } i=j \quad \varepsilon_{i j}^{c h e}\left(c_{N}^{\text {tot }}\right)=\frac{V\left(c_{N}^{\text {tot }}\right)^{1 / 3}-V_{r e f}^{1 / 3}}{V_{r e f}^{1 / 3}} \\
\text { for } i \neq j \quad \varepsilon_{i j}^{c h e}=0
\end{gathered}
$$

\subsection{Computational implementation of trapping}

The amount of free nitrogen after trapping, i.e. the concentration of residual nitrogen, $c_{N}^{r e s}$, can be found using Eq. 13 from

$$
K_{M e N}=c_{C r}^{r e s} \cdot\left(c_{N}^{r e s}\right)^{n}
$$


Computationally, the calculation of residual nitrogen and chromium is done sequentially by calculating the residual nitrogen assuming that residual chromium concentration in the equation above is equal to the free chromium concentration before trapping, so

$$
c_{C r}^{r e s} \text { before trapping } \cdot\left(c_{N}^{\text {res }} \text { after trapping }\right)^{n}=K_{M e N}
$$

The concentration of trapped nitrogen, $c_{N}^{t r}$, is then found by

$$
c_{N}^{t r}=c_{N}(t, z)-c_{N}^{r e s}
$$

and the trapped chromium, $c_{C r}^{t r}$, by

$$
c_{C r}^{t r}=\frac{c_{N}^{t r}}{n}
$$

The concentration of residual chromium after trapping, $c_{C r}^{r e s}$, is then found as

$$
c_{C r}^{r e s}=c_{C r}(t, z)-c_{C r}^{t r}
$$

It is noted that this sequential modeling induces a slight error, but for small time steps it is deemed negligible.

On incorporating trapping in the model for nitrogen diffusion only residual nitrogen is considered to diffuse, while the surface flux depends on the total concentration of nitrogen in the surface:

$$
c_{N}^{t o t}=c_{N}^{t r}+c_{N}^{r e s}
$$

It should be noted that the diffusion coefficient also depends on the total nitrogen concentration.

\section{Results and discussion}

\subsection{Effects of trapping and concentration dependent diffusion coefficient}

The combined effect of a composition-dependent diffusion coefficient of nitrogen and the role of trapping on the developing concentration profile is investigated in this section. For this purpose nitriding at $718 \mathrm{~K}$ for 22 hours is considered, using a nitriding potential of $1000 \mathrm{~atm}^{-1 / 2}$. The concentration-dependent diffusion coefficient is given in Eq. A-1. For the calculations with a constant diffusion coefficient, the average value over the composition range is taken. For diffusion, in all cases the sample was considered infinitely thick, as compared to the diffusion depth range, i.e. diffusion into a semi-infinite solid can be considered. The nitrogen concentration-depth profiles were calculated for the case of no trapping, $K_{C r N}=\infty$, full trapping $K_{C r N}=0$, and intermediate trapping for solubility products $K_{C r N}=10^{7}, K_{C r N}=10^{8}$ and $K_{C r N}=10^{9}$. For these three cases of intermediate trapping, trapping occurs for nitrogen concentrations higher than approximately 
$700 \mathrm{~mol} . \mathrm{m}^{-3}, 4600 \mathrm{~mol} . \mathrm{m}^{-3}$ and $41600 \mathrm{~mol} . \mathrm{m}^{-3}$, respectively. The concentration profiles were calculated under the assumption that no stress develops in the case and that the surface reaction is infinitely rapid, i.e. Eq. 14 was omitted.

The results of the calculations are presented in Fig. 3 a) and b) for constant diffusivity and concentration-dependent diffusivity, respectively. The effect of trapping is most easily observed in Fig. 3a for a constant diffusivity. No trapping yields the usual complementary error-function profile, with a concentration gradient that decreases gradually with depth (black line in Fig. 3a). Full trapping leads to an abrupt transition to zero nitrogen concentration (dashed line in Fig. 3a). Intermediate trapping has as a consequence that a tail appears to the concentration profile beyond the depth where the solubility product is reached. The arrows in Fig. 3a indicate where this discontinuity in the slope to the concentration profile occurs, corresponding to the nitrogen concentrations given above, marking the combination of nitrogen concentration and the depth below which no trapping occurs. Furthermore, a smoothening of the aforementioned abrupt transition from high to low nitrogen concentration is obtained for intermediate trapping. This is most clearly reflected by the profile for $\mathrm{K}_{\mathrm{CrN}}=10^{7}$. The effect of a concentration-dependent diffusion coefficient that increases with nitrogen content, reaches a maximum and thereafter decreases with nitrogen content (see Appendix A1) is reflected in Fig. 3b. Analogous to the observations in Fig. 3a a discontinuity in the slope is observed (marked by arrows) for the concentration and depth below which no trapping occurs. 


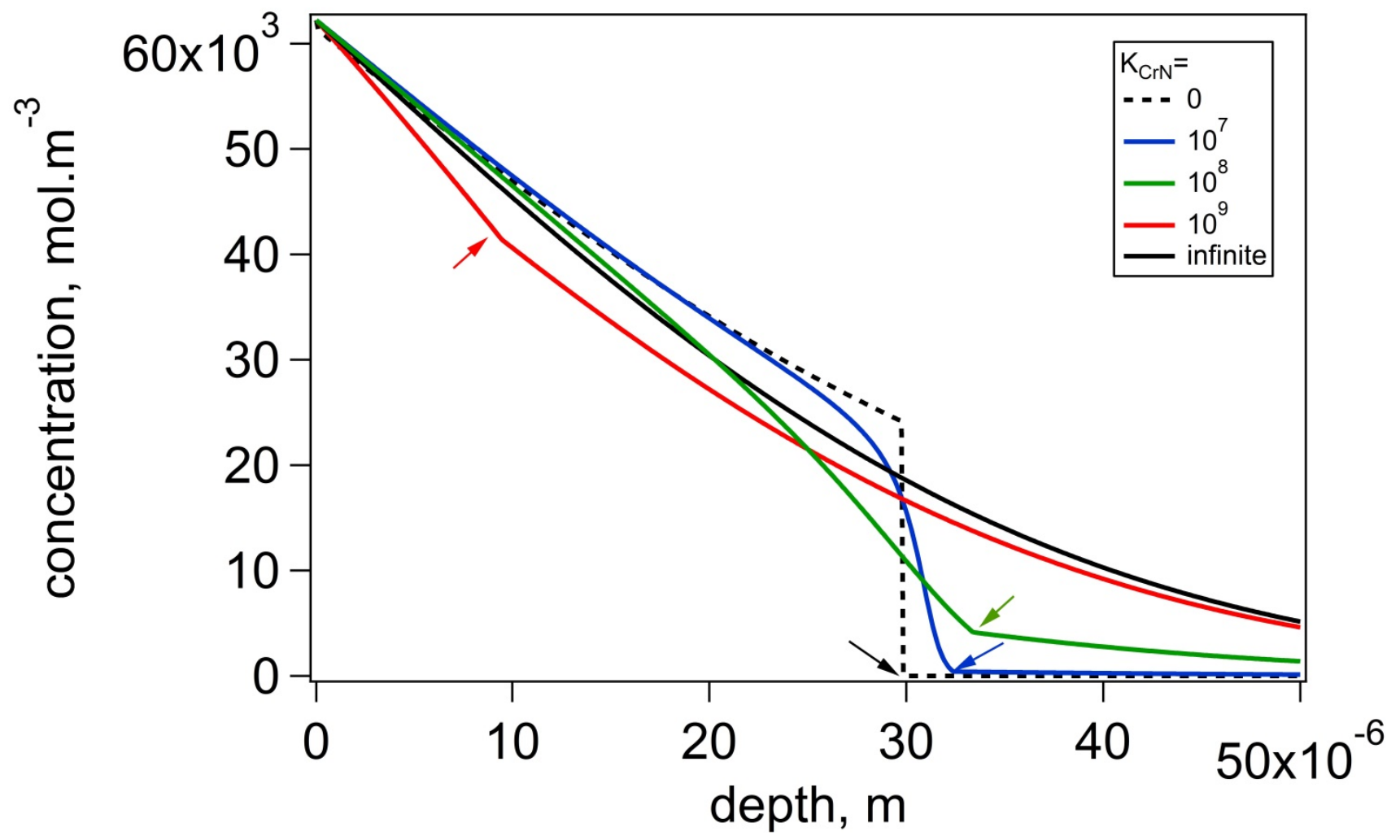

a. 


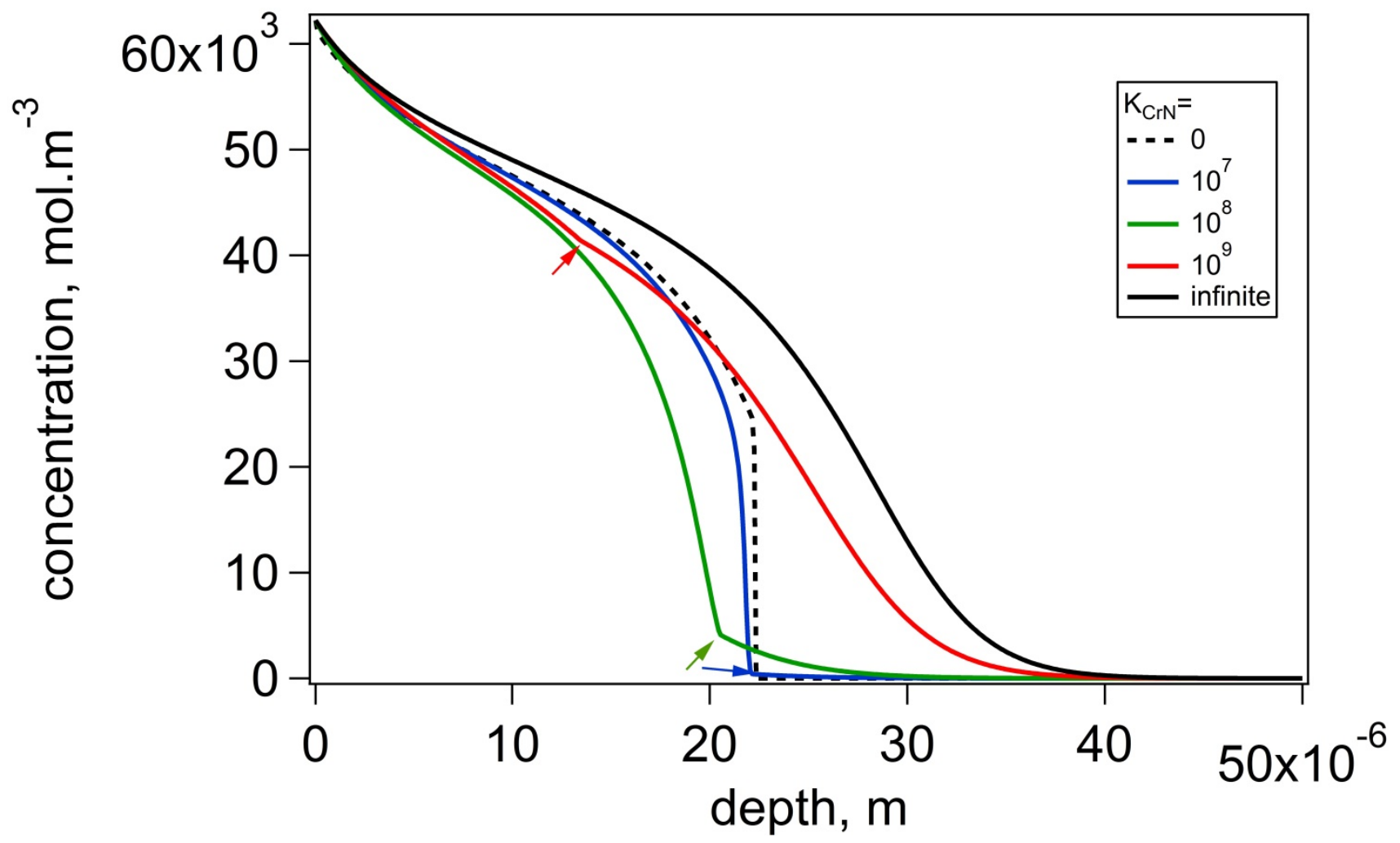

b.

Figure 3 - Concentration-depth profiles calculated assuming a) constant diffusion coefficient and b) concentration dependent diffusion coefficient (cf. Appendix A1), for no trapping, $K_{C r N}=\infty$, full trapping $K_{C r N}=0$, and intermediate trapping for solubility products $K_{C r N}=10^{7}, K_{C r N}=10^{8}$ and $K_{C r N}=10^{9}$ of diffusing nitrogen atoms by chromium atoms. The arrows mark the concentrations (and depths) below which no trapping occurs. Eq. 14 was omitted, implying that the surface reaction was presumed infinitely rapid.

\subsection{The role of the surface reaction on evolution of composition-depth profiles}

The competition of the fluxes of nitrogen arriving at and leaving from the surface was calculated for a concentrationdependent diffusivity, intermediate trapping $K_{C r N}=10^{7}$ and $K_{M e N}=10^{9}$ (cf. Fig. 3b), and different values of the reactionrate constant $k$ in Eq. 14. Again nitriding at $\mathrm{K}_{\mathrm{N}}=1000 \mathrm{~atm}^{-1 / 2}$ at $718 \mathrm{~K}$ is considered. The evolution of the concentrationdepth profile with time for $k=5 \cdot 10^{-7} \mathrm{~m} \cdot \mathrm{s}^{-1}$ and $k=5 \cdot 10^{-10} \mathrm{~m} \cdot \mathrm{s}^{-1}$ is shown in Fig. 4 for $K_{C r N}=10^{7}$, while the evolution of the surface concentration for various values of $k$ is displayed in Fig. 5. As above, the role of stress is omitted. 

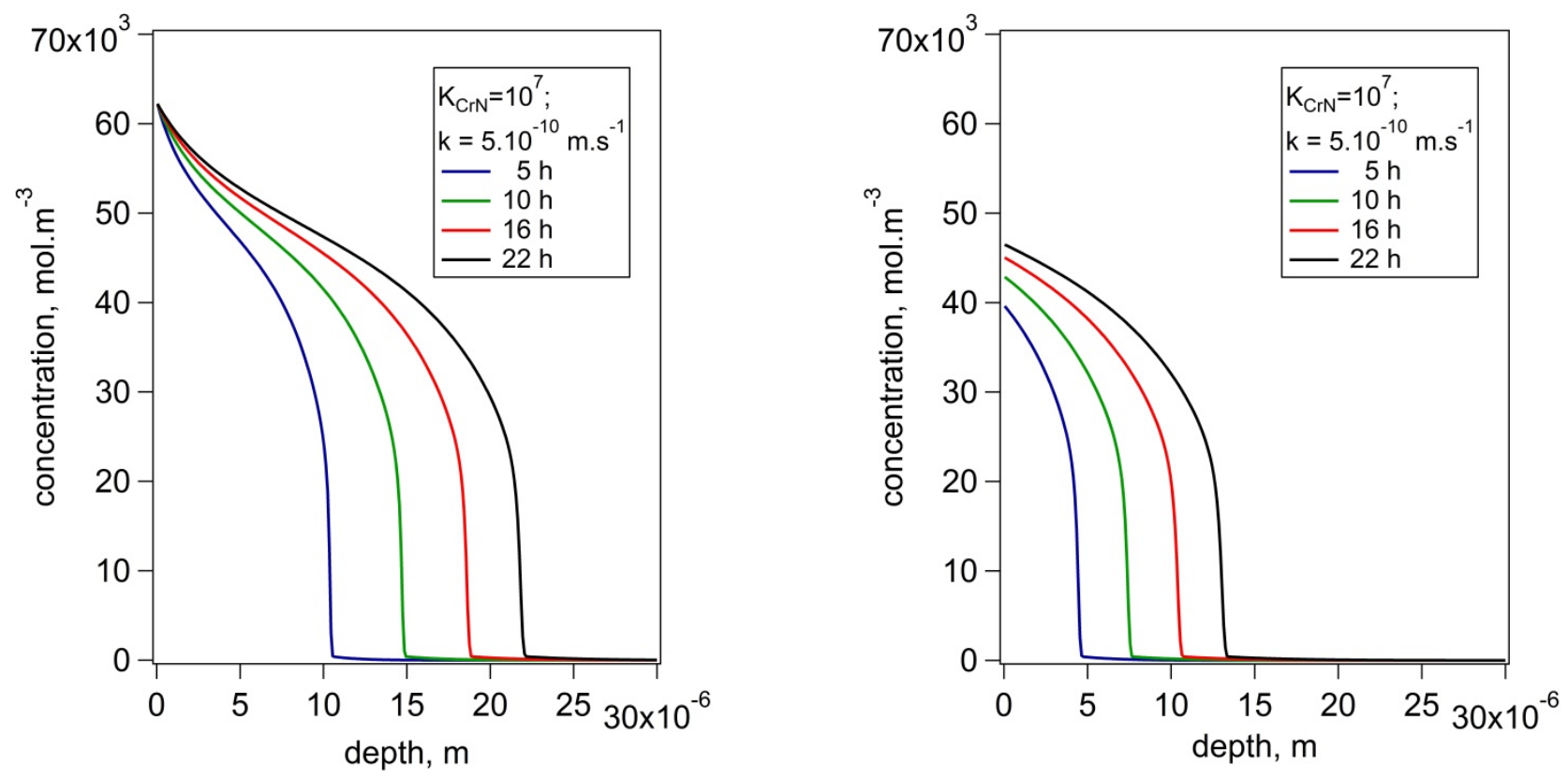

Figure 4 - Evolution of the concentration-depth profile with time for $K_{C r N}=10^{7}, k=5 \cdot 10^{-7} \mathrm{~m} . \mathrm{s}^{-1}$ and $k=5$. $10^{-10} \mathrm{~m} \cdot \mathrm{s}^{-1}$, for nitriding with a nitriding potential of $1000 \mathrm{~atm}^{-1 / 2}$. 


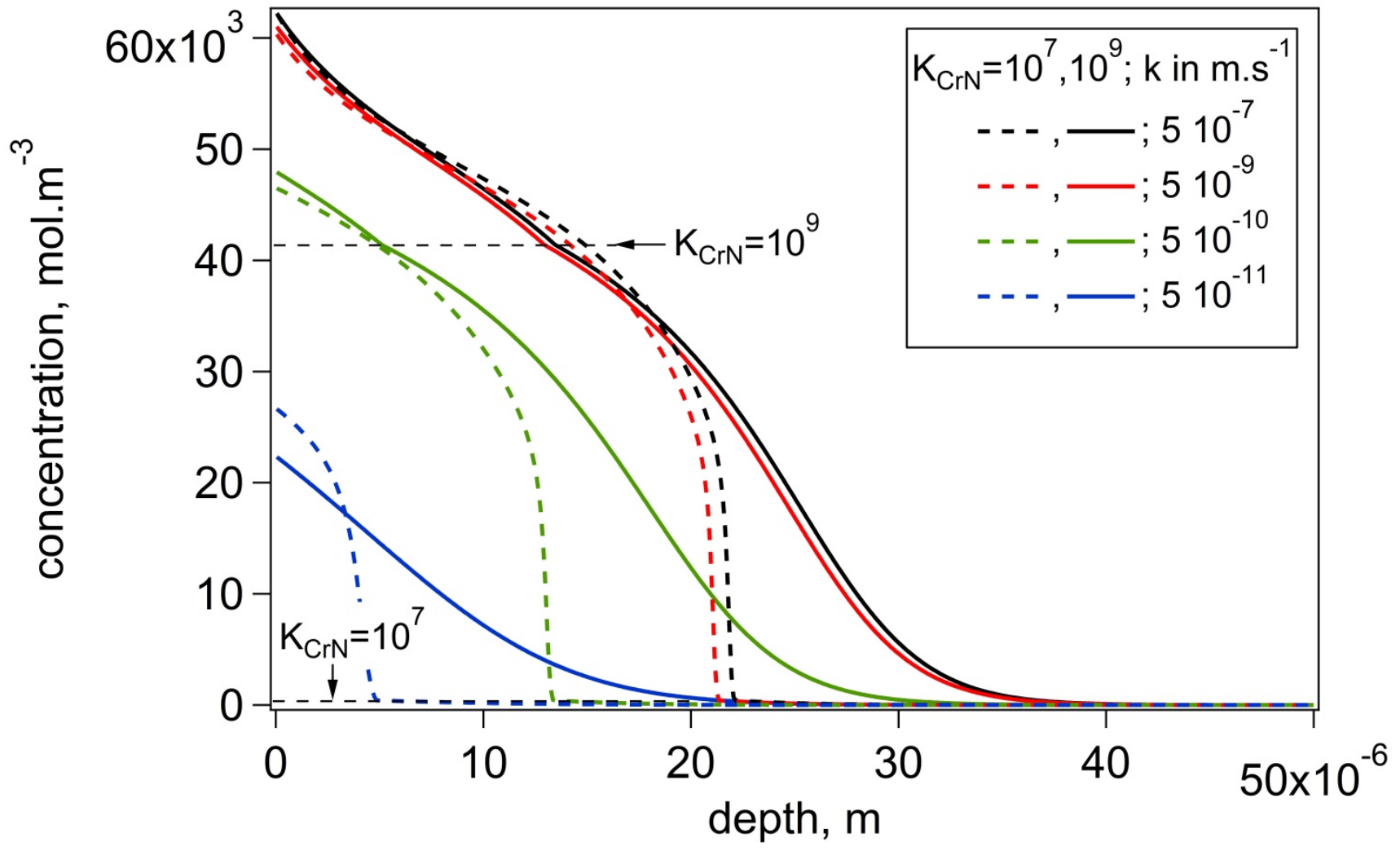

Figure 5 - Evolution of the surface concentration for various values of $k$, for $K_{C r N}=10^{7}$ (thin lines) and $K_{C r N}=10^{9}$ (thick lines) for nitriding of $22 \mathrm{~h}$ at $718 \mathrm{~K}$ at $K_{N}=1000 \mathrm{~atm}^{-1 / 2}$.

The evolution of the concentration profile in Fig. 4 shows that the reaction rate constant of the surface reaction leads to the same surface concentration for all investigated times if $k=10^{-7} \mathrm{~m} \cdot \mathrm{s}^{-1}$. This indicates that (imposed) local equilibrium between nitrogen in the gas phase and nitrogen in the solid phase is achieved at the surface. For a lower value of the reaction rate constant $\left(k=510^{-10} \mathrm{~m} \cdot \mathrm{s}^{-1}\right)$, the surface concentration increases gradually with nitriding time. In Fig. 5 the concentration profiles obtained after nitriding for $22 \mathrm{~h}$ at $718 \mathrm{~K}$ are shown for various combinations of $K_{C r N}$ and $k$. Clearly, the surface concentration of nitrogen attained after 22h decreases with a reduction of the reaction rate constant of the surface reaction. Moreover, the incorporation of trapping and the value of $K_{C r N}$ have an important influence on the total amount of nitrogen incorporated in the material. Stronger trapping leads to a lower amount of incorporated nitrogen and a steeper case-core transition.

\subsection{Composition induced stress-depth profiles}

The dissolution of interstitials into the solid state is not associated with the nucleation of a new phase, but rather an expansion of the existing lattice. From the relation between lattice parameter and nitrogen concentration, the volumetric 
expansion of the lattice can be calculated, see Appendix A2. Accordingly, the composition-induced strains introduced into the lattice can be calculated with Eq. 16. Firstly, it is assumed that these strains are accommodated purely elastically. The stresses introduced under the assumption of an infinitely thick substrate, i.e. all stress is accumulated in the expanded region, were calculated with Eq. 22 and are shown in Fig. 6, for the composition profiles as displayed in Fig. 4. Not surprisingly, the elastic composition-induced compressive stress-depth profiles reflect the composition-depth profiles from which they were calculated. In this respect it is important to realize that in the present calculations the elastic constants were assumed to be independent of the composition of austenite, because no quantitative data are available of how Young's modulus and Poisson's ratio depend on nitrogen concentration in austenite. It is noted that the calculated stress values are unrealistically high and will never be possible to be supported by the austenitic stainless steels under consideration. Furthermore, the values of the elastic stresses are five times as high as found experimentally with X-ray diffraction stress analysis [37]. Clearly, accommodation of the volume misfit introduced by dissolving nitrogen into austenite should, at least partly, be accommodated by plastic deformation. This is in agreement with the experimental observations of grain rotation and stacking fault introduction in expanded austenite [18,19,20,21].
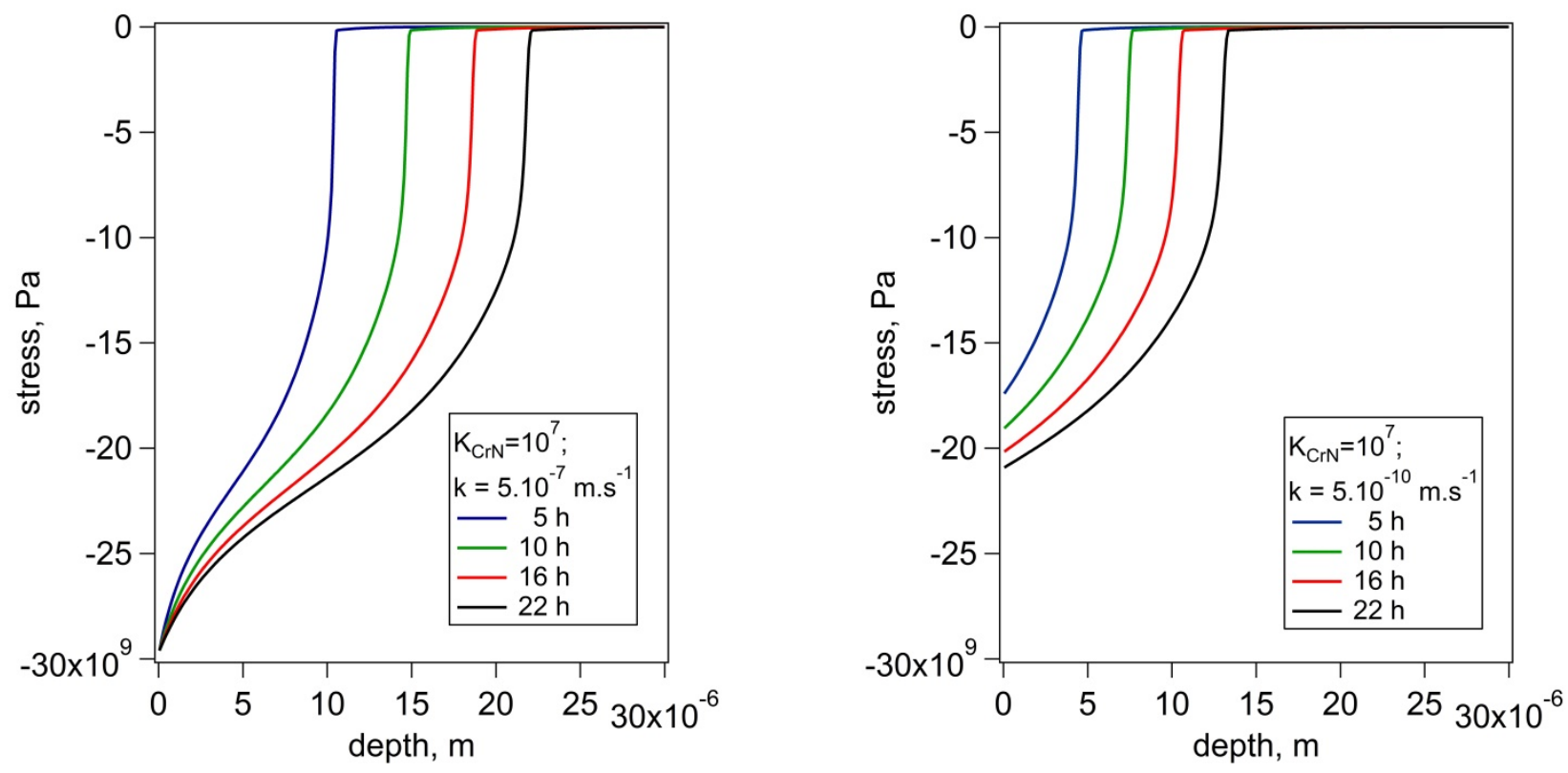

Figure 6 - Compressive composition-induced stress for an infinitely thick substrate, elastic accommodation of the volume expansion and $K_{C r N}=10^{7}$ and $k=5 \cdot 10^{-7} \mathrm{~m} . \mathrm{s}^{-1}$ and $k=5 \cdot 10^{-10} \mathrm{~m} . \mathrm{s}^{-1}$ for selected diffusion times. The corresponding nitrogen concentration-depth profiles are given in Fig. 4.

The effect of the sample thickness on the stress distribution as calculated with Eqs. 18-21 is shown in Fig. 7 for several sample thicknesses, 2L. Only for relatively thin samples substantial tensile stresses are present in the core to compensate for 
the high compressive stresses in the case. Realizing that the stresses in the case are grossly overestimated by the assumption of fully elastic accommodation, it is concluded that for practical situations the tensile stresses in the core can be neglected. This justified omission is therefore implemented in the sequel of this manuscript.

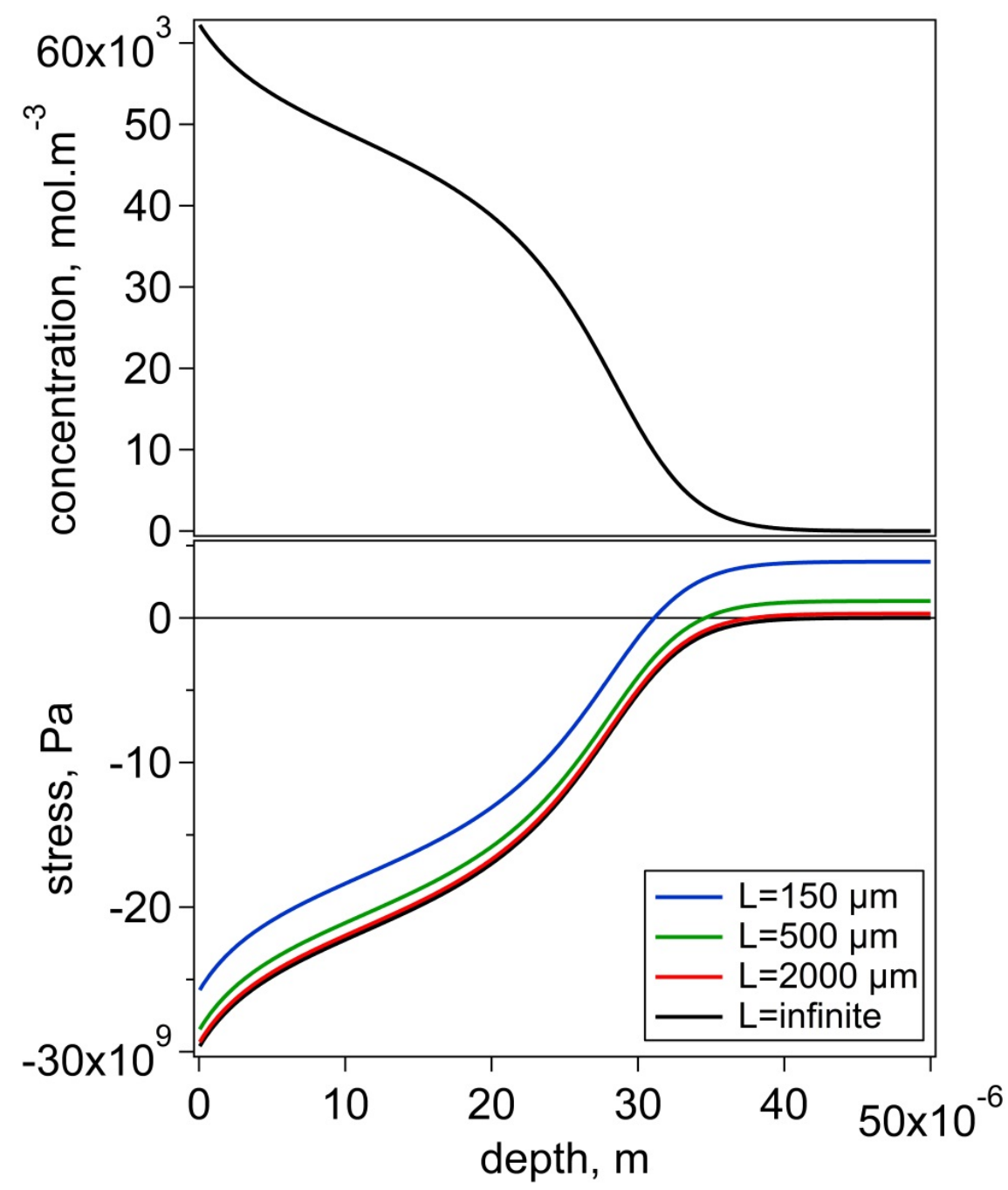

Figure 7 - Effect of thickness of the sample on the predicted stress profile, for $22 \mathrm{~h}$ nitriding with a nitriding potential of 1000 $\mathrm{atm}^{-1 / 2}, k=5 \cdot 10^{-7} \mathrm{~m} . \mathrm{s}^{-1}$ and no trapping (cf. Fig. $3 b$ for $K_{C r N}=$ infinite).

\subsection{Influence of compressive stress on diffusive flux in the sample}

The presence of a gradient in the composition-induced stress is equivalent to an additional (positive or negative) driving force for the diffusion of nitrogen. A compressive stress decreasing with depth, as for the present case (Fig. 6), would imply 
a positive additional driving force for diffusion. It should be noted that in the present calculations it is the stress change with depth that increases the diffusive flux, not the actual level of the stress ${ }^{3}$.

In Fig. 8 the effect of a stress-gradient induced driving force is demonstrated for the same nitriding conditions as in Fig. 5a, i.e. $22 \mathrm{~h}$ at $718 \mathrm{~K}$ at $\mathrm{K}_{\mathrm{N}}=1000 \mathrm{~atm}^{-1 / 2}$, while keeping the surface concentration constant. The lines obtained without considering an effect of the stress on the internal diffusion are reproduced from Fig. 4 and Fig. 6. Evidently, for the exorbitantly huge elastic stresses the stress-gradient induced driving force establishes a concentration profile that reaches about 3.5 times as deep as driven by the concentration gradient alone. This shows the potentially substantial contribution of stress-induced diffusion in expanded austenite, albeit for a grossly overestimated elastic stress.

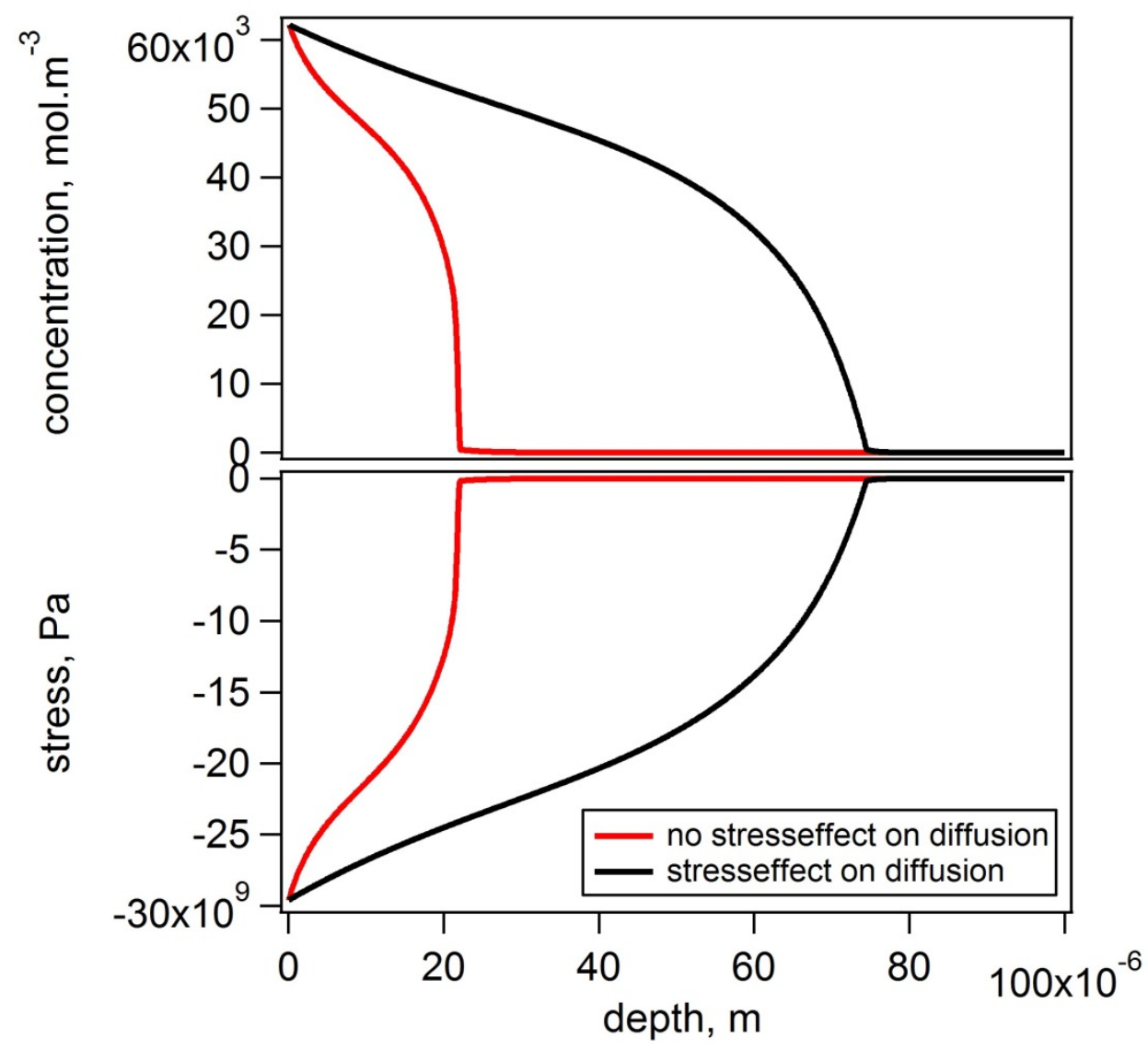

Figure 8 - Effect of taking into account stress on Predicted concentration-depth profiles and stress-depth profiles for nitriding of 316 austenitic stainless steel after 22 hours at $718 \mathrm{~K}$ using a nitriding potential of $1000 \mathrm{~atm}^{-1 / 2}, K_{C r N}=10^{7}$ and $\mathrm{k}^{2}=510^{-7} \mathrm{~m}_{\mathrm{s}}^{-1}$

\footnotetext{
${ }^{3}$ For completeness it is mentioned that the mobility depends on pressure and therefore on the hydrostatic component of the stress. This effect was not taken into consideration in the present work.
} 


\subsection{Influence of compressive stresses on the surface flux}

Compressive stress (or pressure) reduces the solubility of nitrogen in austenite under equilibrium conditions. This will be most clearly manifested by a reduction of the nitrogen concentration at the interface between the solid and gaseous phase, i.e. the surface, where local equilibrium is attempted to be imposed.

The dependence of the surface concentration on the hydrostatic component of the compressive stress is given in Fig. 9 for stainless steel AISI 316 at $718 \mathrm{~K}$ and selected values of the nitriding potential ${ }^{4}$, using Eq. A-14 (for details of the quantitative data extracted from literature data, see Appendix A3 and A4). Evidently, the solubility of nitrogen depends sensitively on the (imposed or residual) stress. Since a lower equilibrium concentration leads to a lower maximum flux through the surface, this indicates that a compressive stress resulting from the chemical strain reduces the nitrogen flux through the surface.

This means, that even though the level of stress does not affect the internal diffusion, as discussed earlier, it does affect the flux through the surface. So even though a stress profile with higher compressive stresses at the surface compared to the centre increases the internal diffusion, it also decreases the flux through the surface.

\footnotetext{
${ }^{4}$ The nitriding potential is proportional to the activity, and thus the chemical potential, of nitrogen in the gas phase (see Appendix A4).
} 


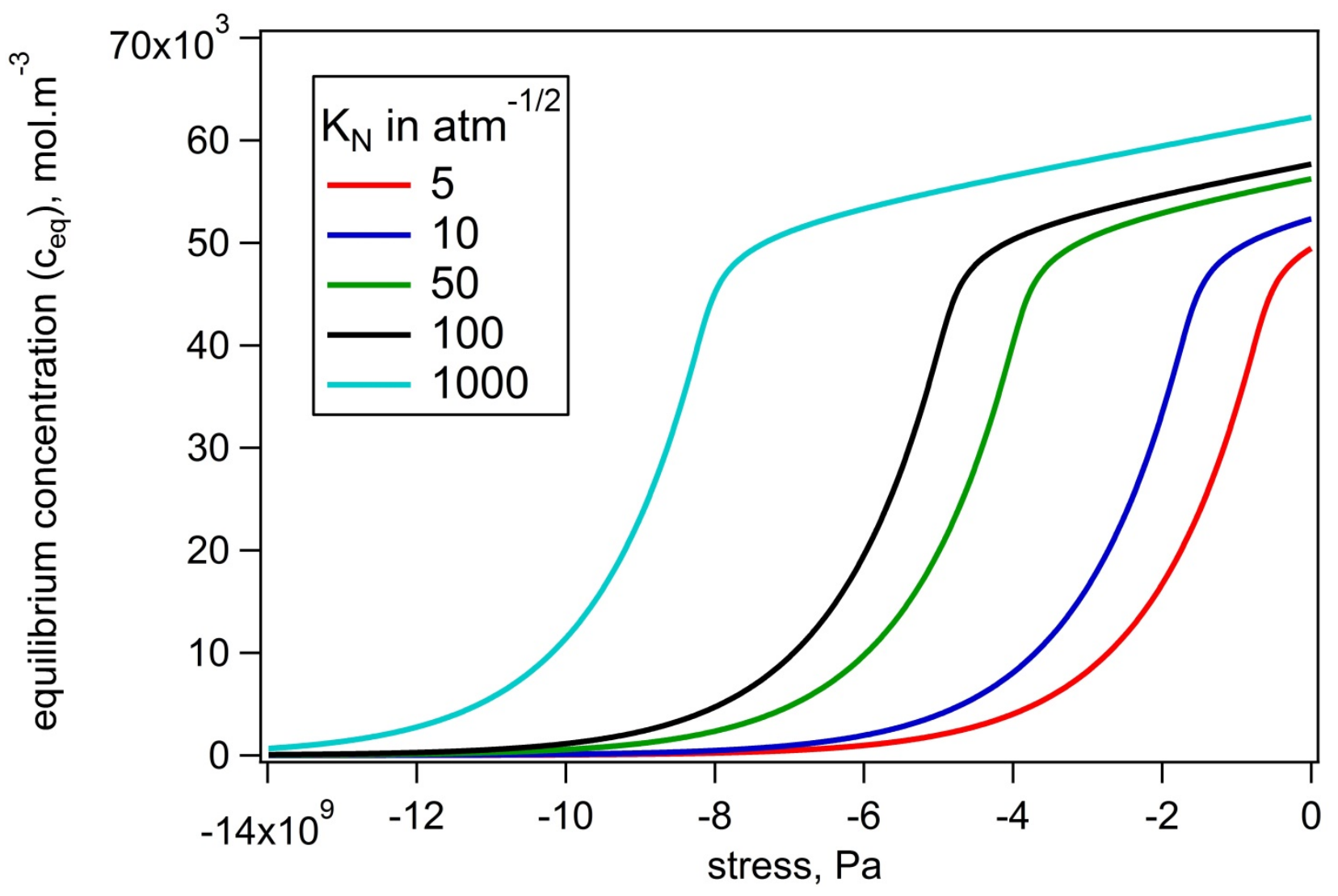

Figure 9 - Equilibrium concentrations as a function of surface stress for varying nitriding potentials, $K_{N}$ (in atm ${ }^{-1 / 2}$ ) (Note that negative values of stress denotes compressive stress).

Implementing the effect of compressive stress on the local equilibrium at the surface, combined with the additional stressinduced driving force for diffusion, leads to the predicted concentration-depth and stress-depth profiles shown in Fig. 10. A reduction by about a factor 2 in the local nitrogen concentration is seen compared to the profile predicted, when the effect of stress on the surface concentration is not taken into account. The lines obtained without considering an effect of the stress on the surface concentration are reproduced from Fig. 8. According to Eq. 14 a lower equilibrium concentration at the surface leads to a lower maximally possible flux through the surface. Nevertheless, the effect of a compressive stress gradient causes a penetration depth of the profile beyond the depth achieved without including the contribution of stressinduced diffusion, (see Fig. 8) despite the substantially smaller chemical contribution to the driving force for diffusion. This indicates that the net effect of the combination of the lower maximal flux through the surface and the larger diffusive flux postpones the establishment of local equilibrium at the surface to guarantee a sufficient uptake of nitrogen to maintain growth of the expanded austenite zone. 


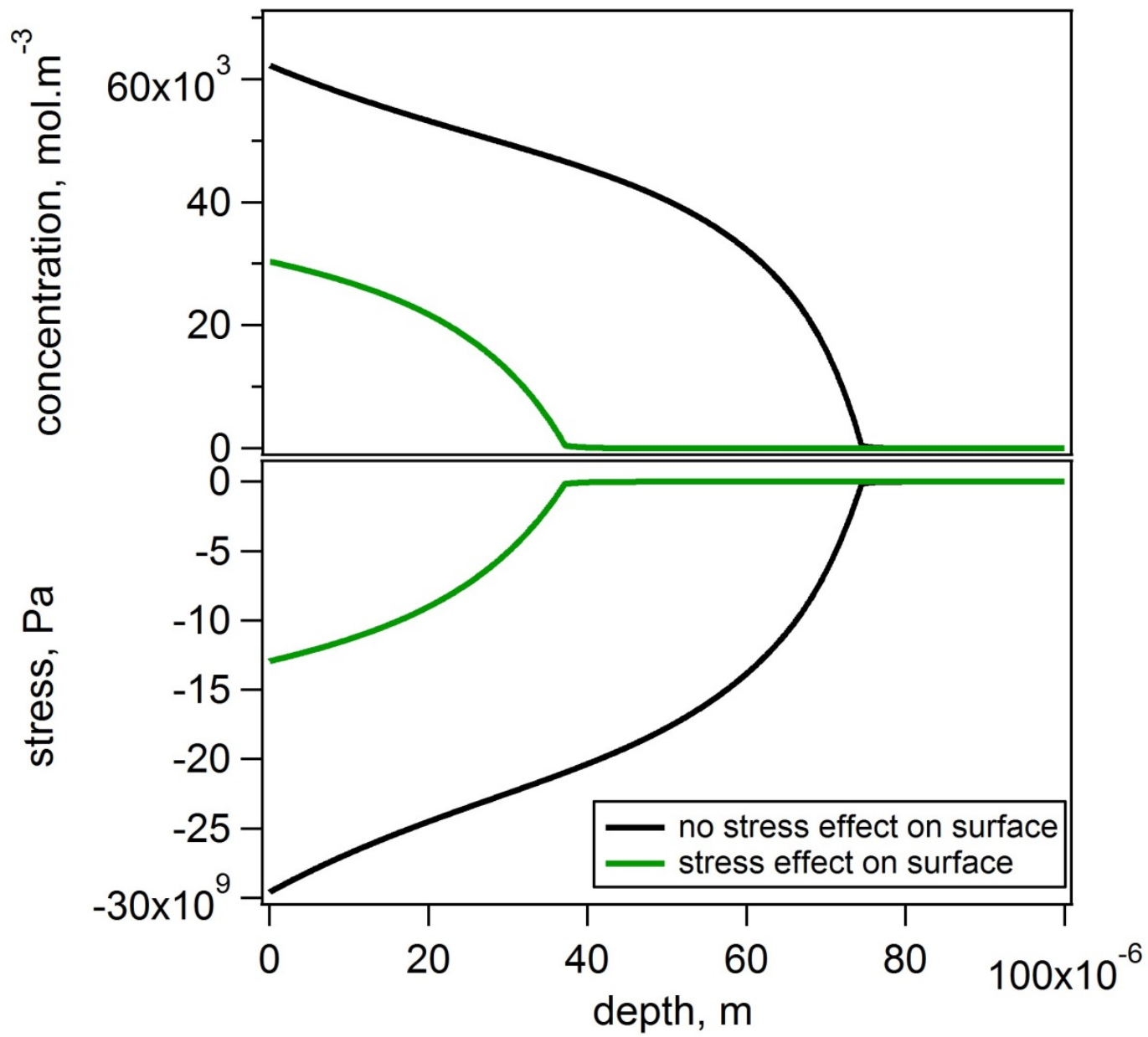

Figure 10 - Predicted concentration-depth profile and stress-depth profile for nitriding of 316 austenitic stainless steel after 22 hours at $718 \mathrm{~K}$ using a nitriding potential of $1000 \mathrm{~atm}^{-1 / 2} K_{C r N}=10^{7}$ and $k=5 \cdot 10^{-7} \mathrm{~m}_{\mathrm{s}} \mathrm{s}^{-1}$.

\subsection{Effect of plasticity on predicted profiles}

Assuming purely elastic accommodation of the lattice expansion of austenitic stainless steel associated with nitrogen dissolution is unrealistic, because the yield stress of austenite is as low as $290 \mathrm{MPa}$ [38].

Concentration-depth and stress-depth profiles are shown for three distinct situations in Fig. 11: assuming purely elastic accommodation of the composition-induced expansion (cf. Fig. 10 for stress affected surface) indicated as "elastic”, plastic accommodation for stress beyond the yield stress of the base material, indicated as "plastic (const. Yield stress)" and the situation where both plasticity and solid-solution hardening are taken into account, indicated as "plastic, Yield stress $=f\left(c_{N}\right)$ ", reflecting the composition-dependence of the yield stress. Details of the input parameters and computational 
method for incorporating the composition-dependent yield stress are described in Appendix A5. Comparison of the profiles for elastic and plastic accommodation shows that taking into account plasticity, the stress level in the expanded austenite zone is very low as compared to when assuming purely elastic accommodation; as was expected. Consequently, for the case of plasticity with constant yield stress, the nitrogen surface concentration and diffusion in expanded austenite would be largely unaffected by the stress and thus a composition-depth profile reminiscent of that for no stress is obtained (cf. Fig. 4). Consistently with the appreciably lower elastic stress in the case, the contribution of stress-induced diffusion is limited, as reflected by the relatively shallow diffusion depth reached. Assuming a concentration-dependent yield stress, implying that solid solution strengthening by nitrogen dissolution in austenite is accounted for, a high nitrogen content is obtained, whilst the compressive residual stresses reach a level of maximally 6 GPa at the surface (Fig. 11).

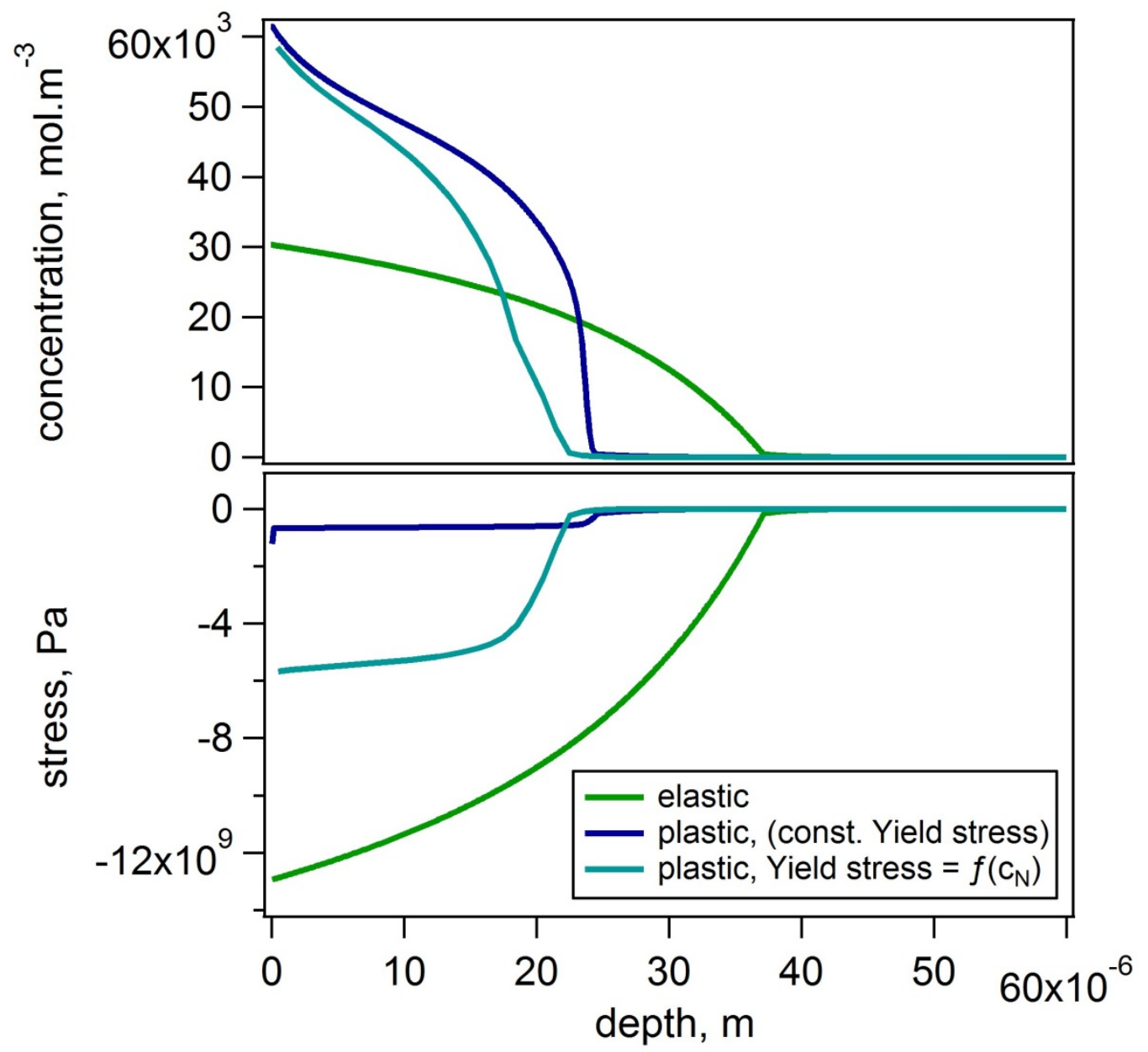

Figure 11 - Simulated concentration-depth profiles and stress-depth profiles using purely elastic accommodation (designated "elastic") of the lattice expansion or elastic-plastic accommodation. For a fixed yield stress the lines denoted "plastic, (const. Yield stress)" are obtained, while the assumption of a concentration-dependent yield stress results in the lines denoted "plastic, Yield stress $=f\left(c_{N}\right)$ ". In all cases the nitriding conditions are $22 \mathrm{~h}$ at $718 \mathrm{~K}$ for $\mathrm{K}_{\mathrm{N}}=1000 \mathrm{~atm}^{-1 / 2}, \mathrm{~K}_{\mathrm{CrN}}=10^{7}$ and $\mathrm{k}=510^{-7} \mathrm{~m}_{\cdot} \mathrm{s}^{-1}$. 


\section{Discussion}

\subsection{Evolution of composition and stress-depth profiles}

In the preceding chapter it was demonstrated how the various parameters influence both the shape of the concentrationdepth profile as well as its evolution with nitriding time. From the systematic analysis in this manuscript it is clear that from the concentration-depth profile alone it is not possible to discriminate between the various models that have so far been presented in the literature. On the one-hand, the adoption of a model presuming a constant diffusion coefficient and trapping of nitrogen atoms, as in Refs. [4,6], can yield concentration-depth profiles of a shape as given in Fig. 3a (in particular for $K_{C r N}=10^{7}$ ). Taking the diffusivity and solubility product, $K_{C r N r}$ (including r), as fitting parameters will certainly allow a satisfactory mathematical description of concentration-depth profiles. On the other hand, the assumption of a concentrationdependent diffusivity as adopted in this work (cf. Appendix A1) also leads to concentration-profiles that resemble those determined experimentally, particularly after including trapping (cf. Fig. 3b). Simulation models like these do not account for the development of residual stress and its influence on the developing concentration-depth profiles. Although the consideration of residual stress was suggested to enhance nitrogen diffusion in expanded austenite, and demonstrated to be able to enhance the case depth by a factor two when the surface concentration was constant [14], further mathematical implementation has so far been pragmatic, assuming an unphysical linear relation between composition and stress and a continuously decreasing diffusion coefficient [36], which obviously is in conflict with the experimentally determined diffusion coefficient for nitrogen in expanded austenite. In the present work the actual lattice expansion of expanded austenite was taken into account and mechanical equilibrium considerations were used to estimate the stress. Moreover, the experimentally observed concentration-dependent diffusion coefficient (measured for stress-free expanded austenite!) were taken as input data in the model, while also the effect of stress on the surface flux and stress-enhanced diffusion was accounted for. Clearly, the present simulations demonstrate that elastic accommodation of the lattice expansion leads to residual stress values far beyond the yield stress of the material, which necessitates an elastic-plastic accommodation of the lattice expansion. Moreover, the residual stress values determined experimentally in expanded austenite are far beyond the yield stress of stainless steel, albeit not as high as the predicted elastic stress values (Fig. 6). Accordingly, solid-solution strengthening by the dissolution of high amounts of interstitials in expanded austenite has to be incorporated, yielding realistic simulations of both concentration-depth and stress-depth profiles over the expanded austenite case (Fig. 11).

The evolution of the case depth, taking a concentration of $5 \mathrm{~mol} \cdot \mathrm{m}^{-3}$ as the minimum nitrogen concentration that belongs to the expanded austenite case, is shown in Fig. 12 for various values of the nitriding potential at a nitriding temperature of 718K. In these simulations all of the effects described in the previous chapter were included. Trapping was included by taking $K_{C r N}=10^{7}$, while the surface reaction was assumed to be in equilibrium $\left(k=5 \cdot 10^{-7} \mathrm{~m}\right.$. $\left.\mathrm{s}^{-1}\right)$. Also, stress-induced diffusion and stress effects at the surface were assumed as well as plasticity with a concentration-dependent yield strength. As follows from Fig. 12, increasing the nitriding potential beyond $K_{N}=100 \mathrm{~atm}^{-1 / 2}$ no influence on the case depth. Note that a linear relation is obtained between squared depth and time, as expected for diffusion-controlled evolution of concentration profiles. The depth range of the expanded austenite case wherein plastic accommodation occurs for the same nitriding 
conditions, is shown in Fig. 13. Comparison of Fig. 12 and Fig. 13 shows that it is nearly unavoidable that plastic accommodation occurs. Only for a very low nitriding potential and associated shallow case depths can plastic accommodation be avoided during nitriding of stainless steel. This is in excellent agreement with the results published in Ref. [20], where lattice rotation, as a consequence of plastic accommodation of residual stress, was observed from the casecore transition to the surface.

So far, carburizing has not been reported to lead to plastic accommodation of lattice expansion and leads to relatively low interstitial contents in the expanded austenite zone. Consistently, the experimental residual stress values reported for carbonstabilized expanded austenite are below $3 \mathrm{GPa}[1,11]$ while the interstitial concentration is maximally $20.10^{3} \mathrm{~mol}^{-3} \mathrm{~m}^{-3}$. For this combination of interstitial content and compressive residual stress, indeed purely elastic accommodation is predicted by Appendix A5 (Fig. A-3).

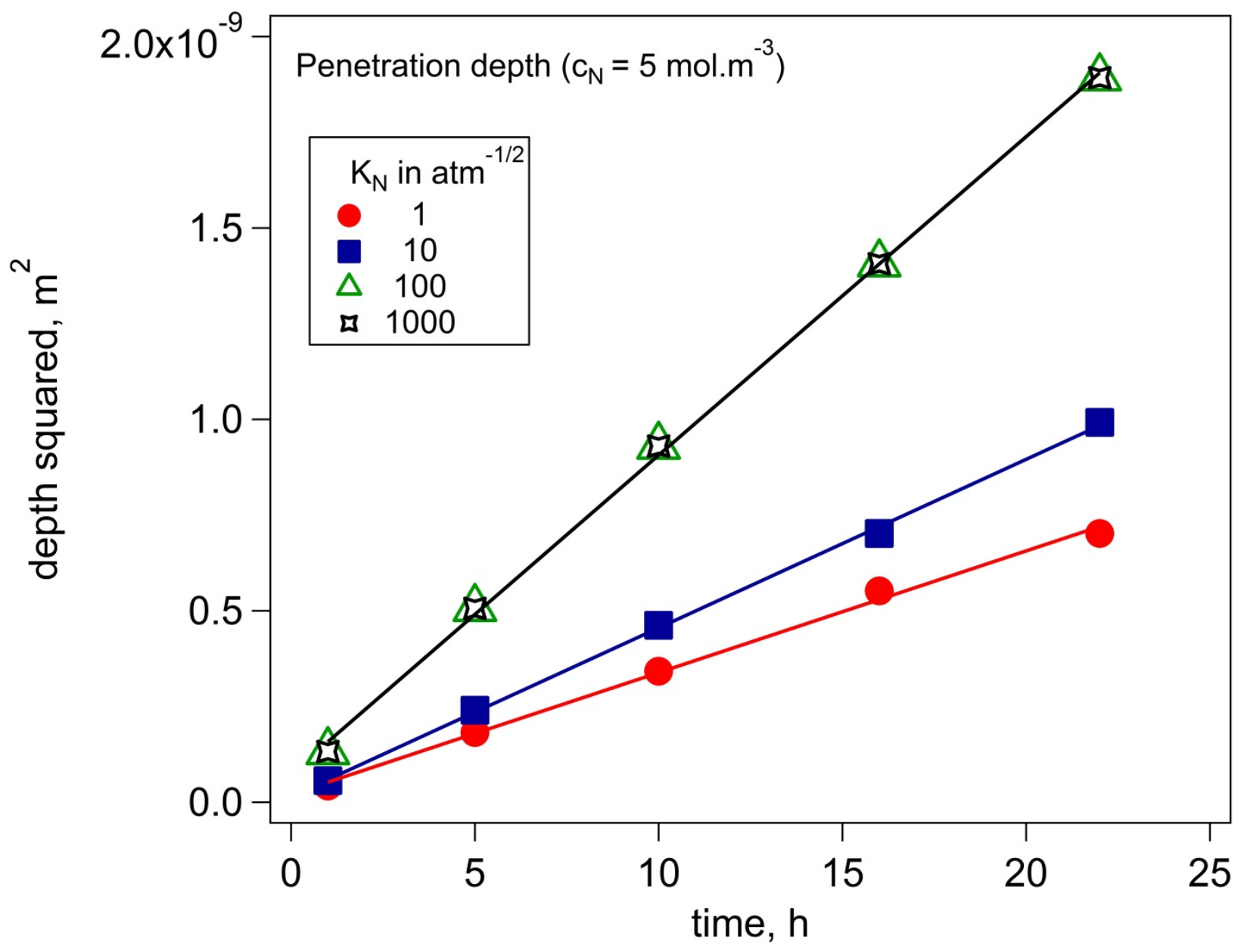

Figure 12 - Case depth $\left(c_{N}>5\right.$ mol.m $\left.{ }^{-3}\right)$ of expanded austenite as a function of nitriding time for various applied nitriding potentials, $K_{N}$, given in atm $^{-1 / 2}$ in the legend. 


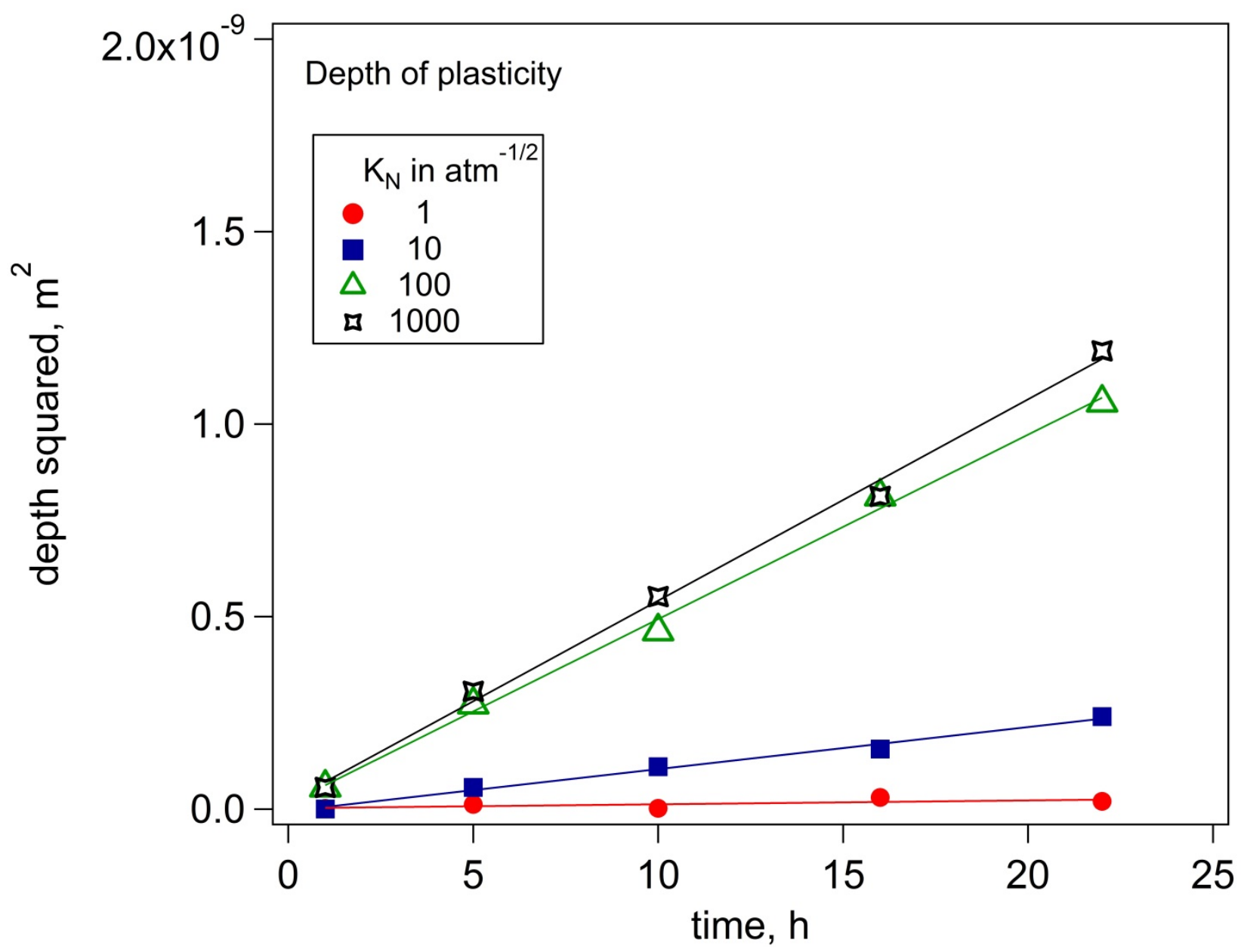

Figure 13 - depth of the plastic zone of expanded austenite as a function of nitriding time for various applied nitriding potentials, $K_{N}$, given in $\mathbf{a t m}^{-1 / 2}$ in the legend.

\section{2 limitations of the model and comparison to experimental work}

The most important novel approaches in the model presented are the coupling of composition and composition-induced stress (rather than a pragmatic linear relation between stress and concentration), and inclusion of plastic deformation, taking into account the occurrence of solid solution strengthening. While experimental data on the concentration-dependent diffusion coefficient was included in the current work, several simplifications and pragmatic approximations were adopted, which are listed below. Also, an anticipation of the effects that these simplifications may have caused are briefly described.

In the simulations, as an approximation for the elastic properties of expanded austenite those for austenitic stainless steel at room temperature were adopted. It was indicated very recently by nano-indentation observations [18] and X-ray residual stress measurements [37] that the elastic properties of expanded austenite vary with nitrogen content and that reversal of 
elastic anisotropy occurs as compared to austenite. As yet the absolute values of Young's modulus and Poisson constant are undetermined, a prediction of the effect of the approximate elastic constants can therefore not be given.

Elastic and plastic properties are also temperature dependent; both the Young's modulus and the yield stress decrease with temperature [38]. Thus, at the nitriding temperature, a lower Young's modulus and a lower yield stress prevail than the values adopted in the model. A lower Young's modulus would cause lower stress levels (for a certain imposed strain) and a lower yield stress would lead to an earlier introduction of plasticity. Both effects result in a lower surface stress.

Moreover, it should be noted that the updating of the plasticity criterion is based on a semi-coupled procedure in which the strengthening and the effect of the concentration-dependent yield stress is considered in a sequential manner. This may affect the stress-predictions, but as a pragmatic approach this is deemed sufficient for the small elements and time-steps considered.

In this work the lattice expansion caused by the dissolution of nitrogen in the austenite lattice was taken from the lattice parameter applying at room temperature. Actually, for the calculation of the concentration (in mol. $\mathrm{m}^{-3}$ ) and the lattice strain, the lattice parameters at the nitriding temperature should have been adopted. Thermal expansion of expanded austenite was recently determined experimentally and it was demonstrated that the linear expansion coefficient depends on the nitrogen content [13].

Thermally-induced stress from the heating and cooling cycle are not considered in the present work, and could lead to a modification of the stress profile that affects the diffusive flux and a modification of the stress-profile after cooling to room temperature. This should be considered in order to more realistically compare the experimental stress values with the calculated values. The influence of thermal stress will be the topic of future research.

Experimentally, no elastic compressive stresses exceeding $10 \mathrm{GPa}$ have been reported and the highest experimentally determined compressive stresses of 7-8 GPa [1] were very recently shown to be a consequence of inappropriate elastic constants, which appear to depend strongly on the nitrogen concentration, such that a reversal of the elastic anisotropy occurs over the composition range [37]. Based on recent insights, the compressive stresses are estimated to be maximally about $5 \mathrm{GPa}$. In this respect the present calculations give an overestimation by $20 \%$. Seen in the light of the limitations mentioned above, this is considered a good agreement

\section{Conclusion}

Nitriding of austenitic stainless steel was modelled taking into account a concentration-dependent diffusion coefficient and short-range ordering of chromium and nitrogen atoms (trapping). Stress-depth profiles were predicted from the lattice expansion caused by the interstitial nitrogen atoms. The interaction between the composition-induced stresses and the diffusion was examined for both purely elastic and elastic-plastic stresses. It can be concluded that: 
- Solid state diffusion is enhanced by the compressive stress gradient resulting from the nitrogen concentration gradient;

- Assuming purely elastic accommodation of the composition-induced strain, the interaction between stresses and diffusion results in surface stresses in the order of $10 \mathrm{GPa}$, which causes a significant decrease of predicted nitrogen concentration at the surface and faster growth of the expanded austenite case;

- Assuming elastic-plastic accommodation of the composition-induced strain, and a constant yield stress, equal to the yield stress of the austenitic stainless steel, decreases the predicted surface stresses to stresses in the order of 1 $\mathrm{GPa}$, and the predicted surface concentration is significantly increased compared to when assuming purely elastic stresses;

- Taking into account the concentration dependent yield stress in the elastic-plastic approach, results in stresses up to 6GPa and a surface concentration value slightly lower than predicted using the constant yield stress of the austenitic stainless steel. The thus obtained composition-depth and stress-depth profiles are in favourable agreement with experimental results.

\section{References}

[1] T. L. Christiansen, M. A. J. Somers, Low-temperature gaseous surface hardening of stainless steel: The current status, Int. J. Mater. Res., 100 (2009) 1361-1377

[2] H. Dong, S-phase surface engineering of Fe-Cr, Co-Cr and Ni-Cr alloys, Int. Mater. Rev., 55 (2010) 65-98

[3] M.A.J. Somers and T.L. Christiansen, "Low-Temperature Surface Hardening og Stainless Steels," in ASM Handbook - Heat treating of Iron And Steels, vol. 4D, ASM International, 2014, pp. 439-450

[4] S. Parascandola, W. Möller D.L. Williamson, The nitrogen transport in austenitic stainless steel at moderate temperatures, Appl. Phys. Lett., 76 (2000) 2194-2196

[5] J. Oddershede, T.L. Christiansen, K. Ståhl, M.A.J. Somers, Extended X-ray absorption fine structure investigation of nitrogen stabilized expandend austenite, Scr. Mater., 62 (2010) 290-293

[6] A. Martinavicius, G. Abrasonis, W. Möller, Influence of crystal orientation and ion bombardment on thenitrogen diffusivity in single-crystalline austenitic stainless steel, J. Appl. Phys., 110 (2011) 074907

[7] T.L. Christiansen, M. A. J. Somers, Determination of the concentration dependent diffusion coefficient of nitrogen in expanded austenite, Int. J. Mater. Res., 99 (2008) 999-1008

[8] T.L. Christiansen, K. V. Dahl, M. A. J. Somers, Simulation of nitrogen concentration depth profiles in low temperature nitrided stainless steels, Defect Diffus. Forum, 258-260 (2006) 378-383

[9] T. Christiansen, M. A. J. Somers, Evaluation of diffusion coefficients from composition profiles - the influence of trapping, Defect Diffus. Forum, 258-260 (2006) 384-389

[10] T.L. Christiansen, K. V. Dahl, M. A. J. Somers, Nitrogen diffusion and nitrogen depth profiles in expanded austenite: Experimental assessment, numerical simulation and role of stress, Mater. Sci. Technol., 24 (2008) 159167

[11] T.L. Christiansen, M. A. J. Somers, Stress and composition of carbon stabilized expanded austenite on stainless steel, Metall. Mater. Trans. A, 40A (2009) 1792-1798

[12] T. Christiansen, Ph. D. Thesis: Low temperature surface hardening of stainless steel. Technical University of Denmark, 2004

[13] B. Brink, K. Ståhl, T.L. Christiansen, M.A.J. Somers, Thermal expansion and phase transformations of nitrogenexpanded austenite studied with in situ synchotron x-ray diffraction, J. Appl. Crystallogr., 47 (2014) 819-826 
[14] T. L. Christiansen, M.A.J. Somers, The influence of stress on interstitial diffusion- Carbon diffusion data in austenite revisited, Defect Diffus. Forum, 297-301 (2010) 1408-1413

[15] A. Galdikas, T. Moskalioviene, Stress induced nitrogen diffusion during nitriding of austenitic stainless steel, Comput. Mater. Sci., 50 (2010) 796-799,

[16] T. Moskalioviene, A. Galdikas, Modeling of nitrogen pentration in polycrystalline AISI 316L stainless steel, Surf. Coat. Technol., 205 (2011) 3301-3306

[17] T.L. Chistiansen, M.A.J. Somers, Avoiding ghost stress on reconstruction of stress- and compostion-depth profiles from destructive X-ray diffration depth profiling, Mater. Sci. Eng. A, 424 (2006) 181-189

[18] J.C. Stinville, C. Tromas, P. Villechaise, C. Templier, Anisotropy changes in hardness and indentation modulus induced by plasma nitriding of 316L polycrystalline stainless steel, Scr. Mater., 64 (2011) 37-40

[19] J.C. Stinville, P. Villechaise, C. Templier, J. P. Rivière, M. Drouet, Lattice rotation induced by plasma nitriding in a 316L polycrystalline stainless steel, Acta Mater., 58 (2010) 2814-2821

[20] C. Templier, J. C. Stinville, P. Villechaise, P. O. Renault, G. Abrasonis, J. P. Rivière, A. Martinavicius, M. Drouet, On lattice plane rotation and crystallographic structure of the expanded austenite in plasmanitrided AISI 316L steel, Surf. Coat. Technol., 204 (2010) 2551-2558

[21] T. Christiansen, M. A. J. Somers, Controlled Dissolution of Colossal Quantities of Nitrogen in Stainless Steel, Metall. Mater. Trans. A, 37A (2006) 675-682

[22]F. C. Larche, J. l. Cahn, The effect of self-stress on diffusion in solids, Acta Metall., 30 (1982) 1835-1845

[23]R. T. DeHoff, Thermodynamics in materials science. New York,N.Y.: McGraw-Hill, 1993

[24] J.C.M. Li, Physical Chemistry of some microstructural Phenomena, Metall. Mater. Trans. A, 9A (1978) 1353-1380

[25] M.A.J. Somers, IFHTSE Global 21: heat treatment and surface engineering in the twenty-first century, Part 14 Development of compound layer during nitriding and nitrocarburising; current understanding and future challenges, Int. Heat Treat. Surf. Eng., 5, (2011) 7-16

[26] Y. Sun, T. Bell, A numerical model of plasma nitriding of low alloy steels, Mater. Sci. Eng. A, 224 (1997) 33-47

[27]R.E. Schacherl, P.C.J. Graat, E.J. Mittemeijer, The Nitriding Kinetics of Iron-Chromium Alloys; The Role of Excess Nitrogen: Experiments and Modelling, Metall. Mater. Trans. A, 35A (2004) 3387-3398

[28]E.J. Mittemeijer, M.A.J. Somers, Thermodynamics, kinetics, and process control of nitriding, Surf. Eng., 13 (1997) 483-497

[29] M.A.J. Somers, thermodynamics, Kinetics and microstructural evolution of the compound layer; a comparison of the states of knowledge of nitriding and nitrocarburising, Heat Treat. Met., 200. (2000) 92-102

[30]P.B. Friehling, F.W. Poulsen, M.A.J. Somers, Nucleation of iron nitrides during gaseous nitriding of iron; effect of a preoxidation treatment, Z. für Met., 92 (2001) 589-595

[31]J.H. Hattel, Fundamentals of numerical modelling of casting processes. Polyteknisk forlag, 2005

[32] J.H. Hattel, P.N. Hansen, A 1-D analytical model for the thermally induced stresses in the mold surface during die casting, Appl Math Model., 18 (1994)

[33] M.A.J. Somers, Modelling nitriding of iron: From thermodynamics to residual stress, J. Phys. IV Proc., 120 (2004) 13

[34] M.A.J. Somers, E.J. Mittemeijer, Development and relaxation of stress in surface layers; Composition and residual stress profiles in $\gamma^{\prime}$-Fe4N1-x layers on $\alpha$-Fe substrates, Metall. Trans. A, 21 (1990) 189-204

[35] V. Tvergaard, Plasticity and creep in structural materials. Kgs. Lyngby, Denmark: Department of mechanical engineering, Technical University of Denmark, 2001

[36] T. Moskalioviene, A. Galdikas, Stress induced and concentration dependent diffusion of nitrogen in plasma nitrided austenitic stainless steel, Vacuum, 86 (2012) 1552-1557

[37]F.A.P. Fernandes, T.L. Christiansen, G. Winther, M.A.J. Somers, On the determination of stress profiles in expanded austenite by grazing incidence X-ray diffraction and successive layer removal, Acta Mater., 94 (2015) 271-280

[38]316-316L data bulletin - www.aksteel.com 20/7 -2014 
[39] M.A.J. Somers, E.J. Mittemeijer, Layer-growth kinetics on gaseous nitriding of pure iron: Evaluation of diffusion coefficients for nitrogen in iron nitrides, Metall. Mater. Trans. A, 26 (1995) 57-74

[40]F. Bottoli, G. Winther, T.L. Christiansen, M.A.J. Somers, Influence of Plastic Deformation on Low-Temperature Surface Hardening of Austenitic Stainless Steel by Gaseous Nitriding, Metall. Mater. Trans. A, 46A (2015) 25792590

[41]F.A.P. Fernandes, M.A.J. Somers, and T. Christiansen, Determination of stress profiles in expanded austenite by combining successive layer removal and GI-XRD, Adv. Mater. Res., 996 (2014) 155-161 


\section{Appendix A - Input parameters to the model}

\section{A1 - Concentration dependent diffusion coefficient}

The following Lorentzian type expression for diffusion coefficient as a function of concentration for the specific temperature of $718 \mathrm{~K}$ was obtained using the data of Christiansen and Somers [10]

$$
D(c)=3.16 \cdot 10^{-15} \cdot \frac{1}{\pi} \cdot \frac{0.109}{\left(y_{N}-0.4365\right)^{2}+0.109^{2}}
$$

where $y_{N}$ is the fractional occupancy of the octahedral interstices of the f.c.c. lattice with nitrogen atoms.

\section{A2 - determination of volumetric expansion of the lattice with nitrogen concentration}

To find the volume of the unit cell as a function of the concentration for expanded austenite $V\left(c_{N}\right)$, data from Christiansen and Somers [21] of the lattice parameter $a$ corresponding to fractional occupancy, $y_{N}$, was used.

The relation between the nitrogen concentration, $\mathrm{c}_{\mathrm{N}}$, and the nitrogen occupancy, $y_{N}$, is [39]:

$$
c_{N}=\frac{4}{N_{a v}} \cdot y_{N} \cdot \frac{1}{V\left(y_{N}\right)}
$$

where 4 is the number of octahedral interstices per f.c.c. unit cell, $N_{a v}$ is Avogadros number and $V\left(y_{N}\right)$ is the volume of the unit cell in $\left[\mathrm{m}^{3}\right]$ at the given $y_{N}$.

$$
c_{N}=\frac{4}{6.022 \cdot 10^{23}[/ \mathrm{mol}]} \cdot y_{N} \cdot \frac{1}{V\left(y_{N}\right)}
$$

A plot showing the calculated volumes as a function of the fractional occupancy are shown in Fig. A-1. Fitting a polynomium to the data gives a linear fit of

$$
V\left(y_{N}\right)=2.8147 \cdot 10^{-29} \cdot y_{N}+4.7134 \cdot 10^{-29}
$$




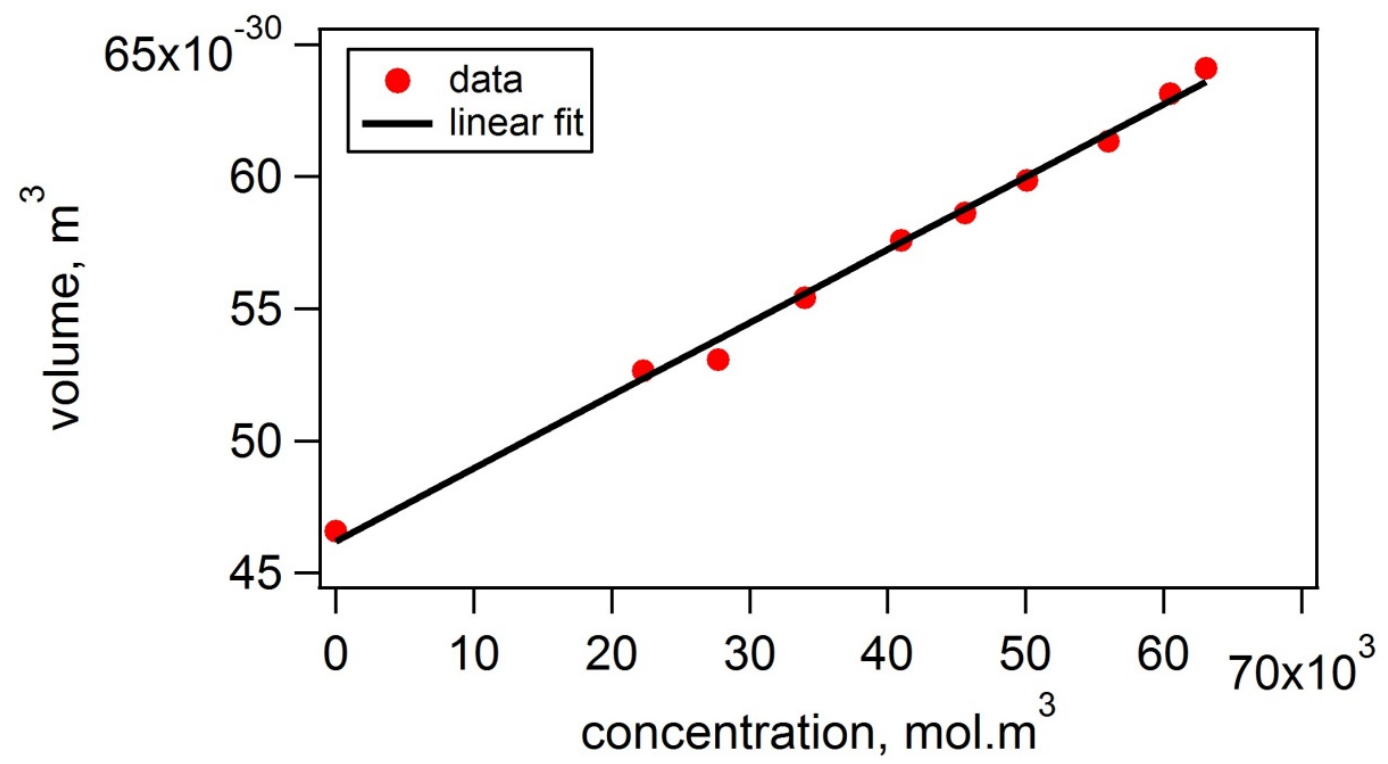

Figure A-1 - unit cell volume as function of nitrogen concentration expressed as fractional occupancy

Inserting the linear fit gives the following expression for calculating concentration as function of fractional occupancy

$$
c_{N}\left[\mathrm{~mol} / \mathrm{m}^{3}\right]=\frac{4}{6.022 \cdot 10^{23} / \mathrm{mol}} \cdot \frac{y_{N}}{2.8147 \cdot 10^{-29} \mathrm{~m}^{3} \cdot y_{N}+4.7134 \cdot 10^{-29} \mathrm{~m}^{3}}
$$

Inverting and reducing gives the following expression for fractional occupancy as function of concentration

$$
y_{N}=\frac{c_{N}}{140924 \mathrm{~mol} / \mathrm{m}^{3}-c_{N} \cdot 0.59717}
$$

Inserting Eq. (A-6) in the expression for volume as a function of fractional occupancy, Eq. (A-4) gives the unit cell volume as function of concentration

$$
V\left(c_{N}\right)=2.8147 \cdot 10^{-29} \mathrm{~m}^{3} \cdot \frac{c_{N}}{140924 \mathrm{~mol} / \mathrm{m}^{3}-c_{N} \cdot 0.59717}+4.7134 \cdot 10^{-29} \mathrm{~m}^{3}
$$

\section{A3 - Relation between activity and nitrogen content; nitrogen absorption isotherms}

Absorption isotherms depict the relation between nitriding potential of an $\mathrm{NH}_{3} / \mathrm{H}_{2}$ gas mixture, i.e. $K_{N}=p_{N H_{3}} / p_{H_{2}}^{\frac{3}{2}}$, and the nitrogen concentration, $c_{N}$. The fractional occupancy of the nitrogen sub-lattice, $y_{N}$, in stress-free austenite was determined experimentally by Christiansen and Somers [21]. Converting the fractional occupancy, $y_{N}$, to concentration, $c_{N}$, Fig. A-2, is obtained. For equilibrium between nitrogen in solid state and imposed nitriding potential the activity of nitrogen in the solid state is linearly proportional to the nitriding potential, $K_{N}$ by [25] 


$$
a_{N}=K_{T} K_{N}
$$

where $K_{T}$ is the equilibrium constant for the dissolution reaction of $\mathrm{N}$ into the solid state from the gas phase, and is a function of temperature and pressure. For dilute solutions Henrian behaviour can be assumed, implying linear proportionality between the nitrogen activity and the nitrogen concentration: $a_{N}=\gamma \cdot c_{N}$. This condition can be assumed only for nitrogen concentrations approaching nil. Since $K_{T}$ is not a function of concentration, it follows from the above for small concentrations $K_{N}=\gamma \cdot \frac{c_{N}}{K_{T}}$. The raw data suggest an exponential relation between $K_{N}$ and $c_{N}$. A function of the following form obeys Henrian behaviour for small $c_{N}$, and was used to parametrize the data

$$
K_{N}=k 1 \cdot \frac{c_{N}}{K_{T}}+k 2 \cdot e^{\frac{c_{N} \cdot k 3+k 4}{\ln \left(K_{T}\right)}}
$$

where k1, k2, k3 and k4 are fitting parameters. Calculating $K_{T}$ for 316 stainless steel the temperature of the measurements $445^{\circ} \mathrm{C}=718.15 \mathrm{~K}$, and no hydrostatic stress gives $K_{T}=2.4256 \cdot 10^{4}$.

For AISI 316 a satisfactory fit of the data at $718 \mathrm{~K}$ was obtained with the following parameters; $k 1=1.7524, k 2=0.9346, k 3=0.0051788$ and $k 4=251.9510$.

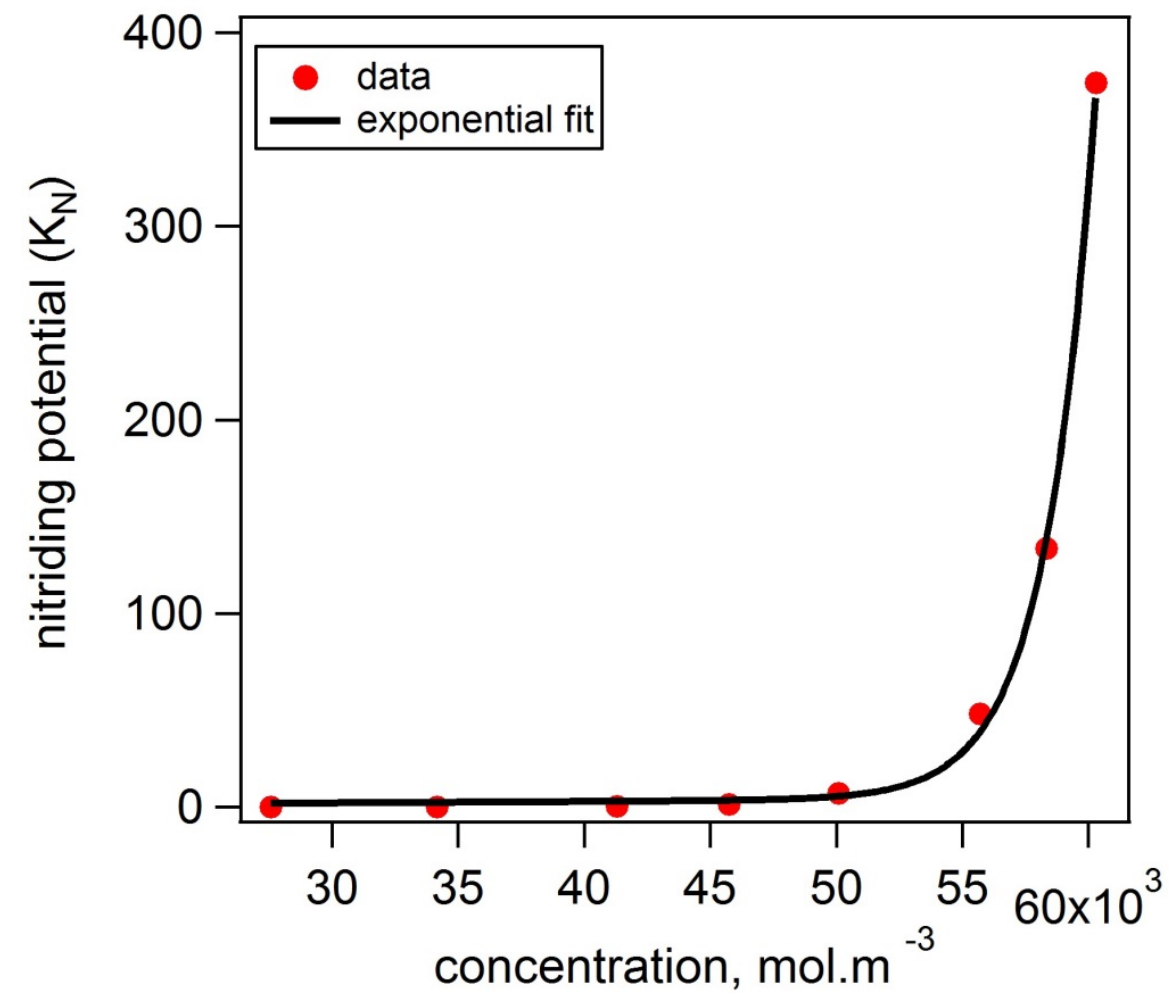

Figure A-2 - fit and - raw data of nitriding potential as function of concentration at $445^{\circ} \mathrm{C}$

\section{A4 - Determination of the effect of stress on the surface flux}


The nitrogen content that can be dissolved in equilibrium with a chemical potential as imposed by a gas phase of known composition depends on the state of stress of the solid, as expressed by Eq. 5. Consequently, the value of $c_{N}^{e q}$, i.e. the nitrogen content in the solid in equilibrium with the gas phase, decreases with the invoked compressive stress in the surface element. At its turn the flux of nitrogen through the surface as given by Eq. 14 is affected as is the actual surface concentration. The concentration of nitrogen in a stressed solid in equilibrium with nitrogen in a gas of known composition follows from equating the chemical potentials of nitrogen in solid and in gas:

$$
\mu^{\text {gas }}=\mu^{\sigma}
$$

The chemical potentials in the solid with and without stress $(\sigma=0)$ are given by

$$
\begin{gathered}
\mu^{\sigma=0}=\mu_{0}+R T \ln (a) \\
\mu^{\sigma}=\mu_{0}+R T \ln (a)-V_{N} \sigma_{H}
\end{gathered}
$$

Hence, comparing the chemical potential in a stressed and a stress-free solid in equilibrium with the same gas leads to

$$
\begin{gathered}
\mu_{0}+R \operatorname{Rln}\left(a^{\sigma}\right)-V_{N} \sigma_{H}=\mu_{0}+R T \ln \left(a^{\sigma=0}\right) \\
\rightarrow a^{\sigma}=a^{\sigma=0} \cdot \exp \left(\frac{V_{N} \sigma_{H}}{R T}\right)
\end{gathered}
$$

Inserting $a_{N}=K_{T} K_{N}$ and realizing that $K_{T}$ depends on pressure, it follows

$$
K_{T}^{\sigma}=K_{T}^{\sigma=0} \cdot \exp \left(\frac{V_{N} \sigma_{H}}{R T}\right)
$$

The relation between the nitrogen concentration and the nitriding potential for a stressed solid follows from inserting Eq. A13 for $K_{T}$ in Eq. A-9

$$
K_{N}=k 1 \cdot \frac{c^{e q}}{{K_{T}}_{T}^{\sigma=0} \cdot \exp \left(\frac{V_{N} \sigma_{H}}{R T}\right)}+k 2 \cdot e^{\frac{c^{e q} \cdot k 3-k 4}{\ln \left(K_{T}{ }^{\sigma=0} \cdot \exp \left(\frac{V_{N} \sigma_{H}}{R T}\right)\right)}}
$$

Since the equation is non-linear and cannot be inverted analytically, the equilibrium concentration was evaluated using Newton-Rhapson iterations.

\section{A5- Concentration dependent yield stress}

The dependence of yield stress on the nitrogen content for austenitic stainless steel is not precisely known, particularly not for the high nitrogen contents of relevance for expanded austenite. Bottoli, et al. [40] investigated two qualities of austenitic stainless steel deformed to various degrees of equivalent strain, and found that the Vickers hardness (HV) and yield stress $\left(\sigma_{y}\right)$ obey the following relation: 


$$
\sigma_{y}[\text { in } \mathrm{MPa}]=-396+3.73 \cdot \mathrm{HV}[\text { in } \mathrm{MPa}]
$$

Realizing that hardness and yield stress both are a measure of the resistance against plastic deformation, it is attempted to obtain an estimate for the concentration dependence of the yield stress from the hardness. Correlating hardness-depth and concentration-depth profiles for nitrided AISI 316 austenitic stainless steel from [41] and converting hardness into yield stress with Eq. A-15, the dependence displayed in Fig. A-3 was obtained. Obviously, the yield stress increases with the concentration until a plateau of constant yield stress is reached. Taking the yield stress of nitrogen free austenite as 290 MPa, a linear fit through the region (c $<14796 \mathrm{~mol}^{-3}{ }^{-3}$ ) where a steep increase in yield stress occurs, results in:

$$
\sigma_{y}[\text { in } \mathrm{MPa}]=0.2424 \cdot c\left[\text { in mol. } \mathrm{m}^{-3}\right]+290
$$

For the plateau the average value is $\sigma_{y}=3848 \mathrm{MPa}$, which is considerably higher that the yield stress of the base material.

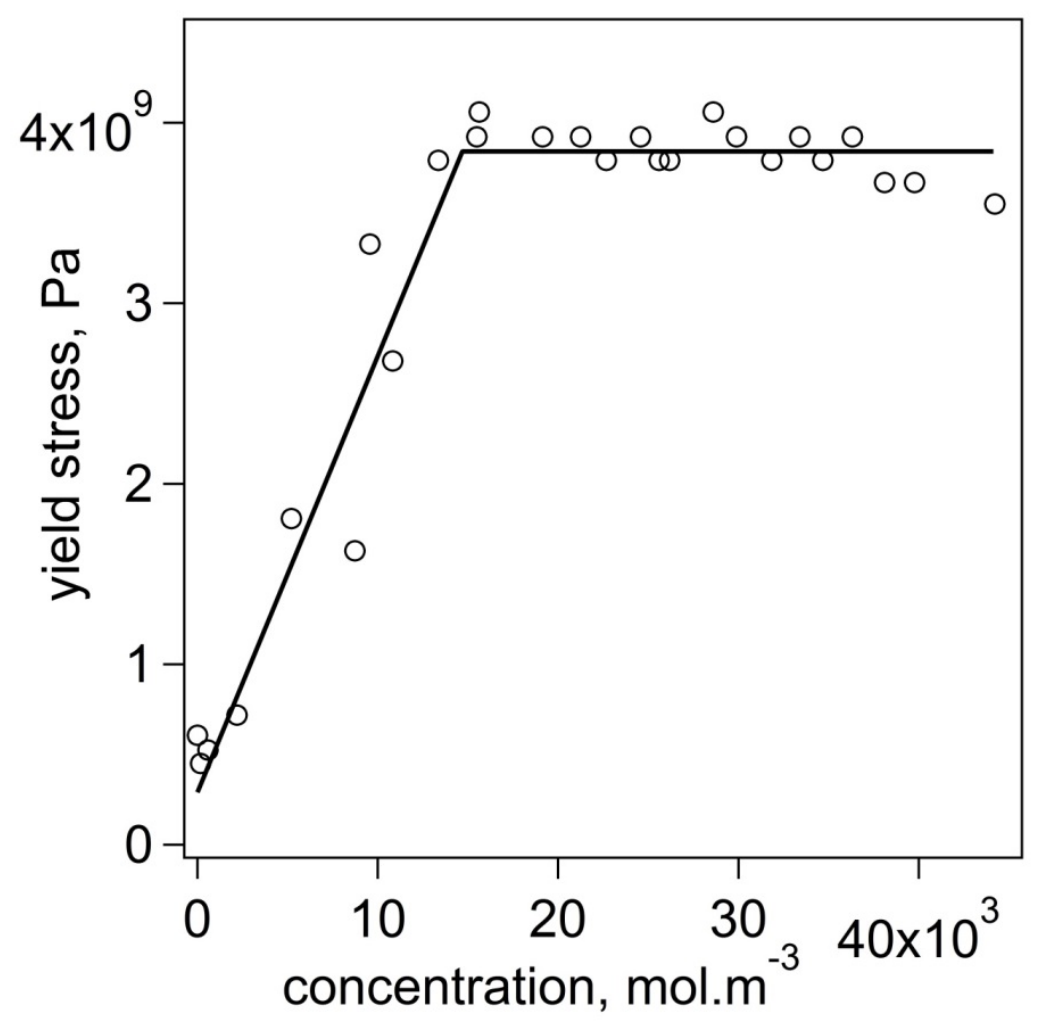

Figure A-3 - Relation between yield stress and nitrogen concentration for AISI 316 stainless steel

Computationally the changing yield stress was implemented by comparing the maximum von Mises stress with the current yield stress resulting from the current concentration, after each time-step. If the concentration dependent yield stress exceeded the maximum von Mises stress, it replaced the value of the maximum von Mises stress, when evaluating plasticity in the next time step. 